\title{
Epitranscriptomics of cardiovascular diseases (Review)
}

\author{
STEFANOS LEPTIDIS $^{1}$, ELENI PAPAKONSTANTINOU ${ }^{1}$, KALLIOPI IO DIAKOU ${ }^{1}$, KATERINA PIEROULI ${ }^{1}$, \\ THANASIS MITSIS ${ }^{1}$, KONSTANTINA DRAGOUMANI ${ }^{1}$, FLORA BACOPOULOU ${ }^{2,3}$, DESPINA SANOUDOU ${ }^{4-6}$, \\ GEORGE P. CHROUSOS ${ }^{2,3}$ and DIMITRIOS VLACHAKIS ${ }^{1-3,7}$ \\ ${ }^{1}$ Laboratory of Genetics, Department of Biotechnology, School of Applied Biology and Biotechnology, \\ Agricultural University of Athens, 11855 Athens; ${ }^{2}$ Laboratory of Molecular Endocrinology, Center of Clinical, \\ Experimental Surgery and Translational Research, Biomedical Research Foundation of the Academy of Athens; \\ ${ }^{3}$ First Department of Pediatrics, Center for Adolescent Medicine and UNESCO Chair on Adolescent Health Care, \\ Medical School, Aghia Sophia Children's Hospital, National and Kapodistrian University of Athens; \\ ${ }^{4}$ Fourth Department of Internal Medicine, Clinical Genomics and Pharmacogenomics Unit, Medical School, \\ 'Attikon' Hospital, National and Kapodistrian University of Athens; ${ }^{5}$ Molecular Biology Division, \\ Biomedical Research Foundation of the Academy of Athens; ${ }^{6}$ Center for New Biotechnologies and Precision Medicine, \\ Medical School, National and Kapodistrian University of Athens, 11527 Athens, Greece; ${ }^{7}$ School of Informatics, \\ Faculty of Natural and Mathematical Sciences, King's College London, London WC2R 2LS, UK
}

Received August 20, 2021; Accepted October 20, 2021

DOI: 10.3892/ijmm.2021.5064

\begin{abstract}
RNA modifications have recently become the focus of attention due to their extensive regulatory effects in a vast array of cellular networks and signaling pathways. Just as epigenetics is responsible for the imprinting of environmental conditions on a genetic level, epitranscriptomics follows the same principle at the RNA level, but in a more dynamic and sensitive manner. Nevertheless, its impact in the field of cardiovascular disease (CVD) remains largely unexplored. CVD and its associated pathologies remain the leading cause of death in Western populations due to the limited regenerative capacity of the heart. As such, maintenance of cardiac homeostasis is paramount for its physiological function and its capacity to respond to environmental stimuli. In this context, epitranscriptomic modifications offer a novel and promising therapeutic avenue, based on the fine-tuning of regulatory cascades, necessary for cardiac function. This review aimed to provide an overview of the most recent findings of key epitranscriptomic modifications in both coding and non-coding RNAs. Additionally, the methods used for their detection and important associations with genetic variations in the context of CVD were summarized. Current knowledge on
\end{abstract}

Correspondence to: Dr Dimitrios Vlachakis, Laboratory of Genetics, Department of Biotechnology, School of Applied Biology and Biotechnology, Agricultural University of Athens, 75 Iera Odos, 11855 Athens, Greece

E-mail:dimvl@aua.gr

Key words: cardiovascular diseases, epitranscriptomics, non-coding RNAs, biotechnology, genetic variants cardiac epitranscriptomics, albeit limited still, indicates that the impact of epitranscriptomic editing in the heart, in both physiological and pathological conditions, holds untapped potential for the development of novel targeted therapeutic approaches in a dynamic manner.

\section{Contents}

1. Introduction

2. Prevalence of epitranscriptomics in CVD and their activity

3. RNA methylation modifications

4. Substitution modifications

5. Other modifications

6. Tools of epitranscriptomic modification research

7. Epitranscriptomic genetic variation and CVD

8. Therapeutic implications of epitranscriptomics in CVD

7. Conclusions

\section{Introduction}

In recent years, great technological leaps in sequencing technologies have enabled the in-depth investigation of the genetic basis of a multitude of human disorders, and they have paved the way for a new era of personalized medicine $(1,2)$. Such breakthrough developments in sequencing technologies have substantiated the deep complexity of associations between genotype and phenotype and revealed unexpected cases, such as those of identical twins carrying the same disease mutations, but exhibiting different clinical features, such as balance problems and the development of blindness (3). Such discrepancies can be attributed to epigenetic and/or epitranscriptomic differences. The term epigenetics, first introduced 
by C.H. Waddington in 1942, refers to the study of the mechanisms and molecules that can perpetuate variable gene activity states in the context of the same DNA sequence (4). Epigenetic mechanisms include DNA methylation, chromatin remodeling, histone modifications, gene activity regulation by non-coding RNA (ncRNA) molecules and protein-protein interactions (5). These mechanisms, which include a vast array of different molecules and pathways, regulate genomic structure and transcriptional activity in response to the ever-changing profiles of cell-intrinsic, cell-cell and cell-extrinsic signals (6).

Epigenetic regulation has been increasingly gaining interest due to its strong relationship with environmental adaptation. As new insights are gained, novel distinctions are also formed, leading to the emerging field of epitranscriptomics. Instead of encompassing all epigenetic regulation, epitranscriptomics focuses on modifications at the RNA level (7). Due to the vast array of effects that coding and ncRNAs exert in regulating the differential response of organisms to environmental stimuli, as well as homeostasis maintenance, epitranscriptomics has turned into an explosive field of research. Several different RNA modification databases have been established throughout the years in an effort to catalogue the plethora of RNA modifications that are continuously being detected. These include databases such as Modomics (https://iimcb. genesilico.pl/modomics/) (8-11), RMBase v2.0 (http://rna.sysu. edu.cn/rmbase/) (12), DARNED (https://darned.ucc.ie/) (13), the RNA Modification Database (https://mods.rna.albany. edu/) (14) and REDIportal v2.0 (http://srv00.recas.ba.infn. it/atlas/) (15), encompassing >172 RNA modifications to date.

Epitranscriptomic changes induced by such mechanisms have been implicated in various diseases and most of them display reversiblechemistry, making epitranscriptomics a promising candidate for providing novel therapeutics (16). As such, a number of reviews have already been published discussing the ever-expanding field of epitranscriptomic modifications, with a limited number focusing on their effects under the prism of cardiovascular disease (CVD). Most notable reviews have focused on N6-methyladenosine $\left(\mathrm{m}^{6} \mathrm{~A}\right)$ modifications, as the most prevalent epitranscriptomic modification and its role in CVD $(17,18)$. Although, Kumari et al $(17)$ featured a section about $\mathrm{m}^{6} \mathrm{~A}$ readers, Chen et al (18) also discussed the potential for $\mathrm{m}^{6} \mathrm{~A}$ modification to influence CVD risk factors. Focusing more on clinical trials investigating epigenetic-sensitive drugs for heart failure (HF), Napoli et al (19) also outlined the discovery of epigenetic biomarkers and signatures of cardiac remodeling. On the other hand, Fischer and Vondriska (20) focused their discussion on epigenetic changes occurring in CVD, but did not expand into RNA modifications, as was also the case for Schiano et al (21), who discussed epigenetic mechanisms underlying the various pathologies encompassed by the CVD umbrella-term. Although the authors mentioned CVD epitranscriptomics as an emerging layer of epigenetic regulation in CVD, they also highlighted the need for further research that covers this subject matter.

In the present review, the most prevalent epitranscriptomic modifications that have been shown to be involved in the field of CVD have been outlined (22), in an effort to extensively cover the area of RNA modifications, without focusing on a single one. This study also briefly discussed the mode of action of each modification and then explored their respective effect on both coding and ncRNAs, including microRNAs (miRNAs/miRs) and long ncRNAs (lncRNAs), in the context of CVD. Furthermore, the current methods of RNA modification detection that have been on the forefront of epitranscriptomic research were also explored in brief. Finally, available data on genetic associations of RNA modifications, as well as therapeutic implications of epitranscriptomic approaches, in the heart were discussed.

\section{Prevalence of epitranscriptomics in CVD and their ac- tivity}

CVD is currently the leading cause of death worldwide, accounting for almost half the total number of deaths (23). CVD encompasses a wide array of heart and vessel-related pathologies, including, but not limited to HF, coronary heart disease, hypertension, hypertrophic and dilated cardiomyopathy, as well as congenital heart disease (24). Accumulating data have shown that cardiovascular risk factors may alter epigenomic patterns and that several cardiovascular biomarkers are associated with epigenetic modifications (25). DNA methylation appears to contribute to processes underlying CVDs, such as atherosclerosis, hypertension and inflammation (26-28). Moreover, epidemiological studies imply that methylation of repetitive sequences such as long-interspersed nucleotide repetitive elements-1 (LINE-1) and Alu elements are associated with CVD (26). Specifically, patients with prevalent ischemic heart disease (IHD) and stroke displayed lower blood LINE-1 methylation, while elevated methylation of Alu elements was associated with CVD and obesity in Chinese individuals (26). Histone modifications have also been implicated in processes, such as hypertension and atherosclerosis, while histone deacetylase 4 overexpression following myocardial infarction (MI) has been shown to increase myocardial fibrosis and cardiac hypertrophy, eventually leading to cardiac dysfunction (29). Although epigenetic regulation has been the focus of attention, RNA modifications have only recently started becoming the focus of CVD researchers.

Epitranscriptomic regulation manifests through the action of different enzymes. Enzymes that modify the RNA itself are called 'writers', while the ones that recognize and remove modifications are termed 'erasers'. Finally, 'readers' are the group of enzymes that bind the modifications themselves $(30,31)$. These different modifications are classified into groups based on their different characteristics. These groups include classification into reversible and non-reversible (where erasers are lacking), substitutional and non-substitutional (32), cap (where the modifications happen to the 5'-end of the RNAs) or internal modifications [where the modifications occur within the 5'- or 3'-untranslated regions (UTRs) or within transcript introns] (33), and finally, modifications on coding or ncRNAs (34). NcRNAs have now been studied extensively and have been proven to have important regulatory effects in both physiological and pathological conditions. The term ncRNAs encompasses a large array of RNA molecules, including, but not limited to the major classes, such as miRNAs, lncRNAs and circular RNAs (circRNAs), as well as transfer RNAs (tRNAs), ribosomal RNAs (rRNAs), small nucleolar RNAs (snoRNAs), small nuclear RNAs (snRNAs) and others (35). ncRNA regulatory roles extend from interacting with RNA/DNA-binding 
proteins, being part of complex structures, interacting with messenger RNA (mRNA) molecules to participating in translation and guiding chemical modifications (35). Through post-transcriptional modifications, ncRNAs display discrete temporal and spatial expression patterns, reflecting a precise regulation of their expression (36).

Epitranscriptomic editing of ncRNAs is quite prevalent during physiological, but also pathological conditions (37). miRNA editing is capable of creating alternative miRNAs, known as isomiRs (38). isomiR Bank, a database integrating $>300,000$ detected isomiRs (https://mcg.ustc.edu. $\mathrm{cn} / \mathrm{bsc} /$ isomir/) (39), gives an estimate of the extent of additional layers of regulation that this editing process can generate. Although, isomiRs were first dismissed as artifacts, follow-up research has shown that almost half of miRNA transcripts are edited, and these edited transcripts can be loaded into the RNA-induced silencing complex and exert their regulatory activity (40). miRNA modifications happen either in the 3 '-end or in the 5'-end sequences. Although, 3'-end editing is more prevalent (41), it mostly influences miRNA stability and activity. 5'-end editing, on the other hand, introduces modifications in the seed sequence, altering the target set of the miRNA and regulating new pathways (42-45). Moreover, circRNA efficiency and translation have been shown to be subject to regulation by distinct RNA modifications, such as $\mathrm{m}^{6} \mathrm{~A}, 5$-methylcytosine $\left(\mathrm{m}^{5} \mathrm{C}\right)$ and pseudouridylation $(\Psi)$ modifications (46), as was also the case for numerous lncRNAs, which have been found to have roles in various CVD-related pathways, such as atherosclerosis and pulmonary hypertension (47).

In the present study, the epitranscriptomic modifications are classified into three major categories. The most prevalent form of epitranscriptomic modification, as in epigenetics, is RNA methylation (Fig. 1), which can affect adenosines in different positions $\left[\mathrm{N}^{1}\right.$-methyladenosine $\left(\mathrm{m}^{1} \mathrm{~A}\right)$, $\mathrm{m}^{6} \mathrm{~A}, 2^{1}-\mathrm{O}$-methylation $\left.(\mathrm{Nm})\right]$, cytosines $\left[\mathrm{m}^{5} \mathrm{C}, 5\right.$-hydroxymethylcytosine $\left(\mathrm{hm}^{5} \mathrm{C}\right)$ ] or guanosines [7-methylguanosine $\left.\left(\mathrm{m}^{7} \mathrm{G}\right)\right](48)$. The second group encompasses substitutional modifications (Fig. 2), which include A-to-I and C-to-U RNA editing $(49,50)$. Finally, the third group of modifications includes all epitranscriptomic changes that do not fall into any of the previous two categories [such as $\Psi$ (51) and 8-oxoguanine (8-OxoG)], but nevertheless, have a proven or implied role in CVD (52) (Fig. 3).

\section{RNA methylation modifications}

$m^{6} A$. One of the most extensively studied RNA modifications in general is the $\mathrm{m}^{6} \mathrm{~A}$ modification. First discovered in $1974(53,54), \mathrm{m}^{6} \mathrm{~A}$ modification comprises the most common chemical addition to eukaryotic RNA. During $\mathrm{m}^{6} \mathrm{~A}$ modification, a methyl group (-CH3) is added to the $\mathrm{N}^{6}$ site of the adenosine residue $\left(\mathrm{m}^{6} \mathrm{~A}\right)(55)$. This event can be detected in snoRNAs, tRNAs, rRNAs and other ncRNAs, and eventually represents $0.2-0.6 \%$ of all adenosine in mammalian mRNA (56). Specifically, $80 \%$ of the methylation that the total transcriptome undergoes is through the $\mathrm{m}^{6} \mathrm{~A}$ modification (57). In terms of localization, the distribution of $\mathrm{m}^{6} \mathrm{~A}$ follows a specific pattern in RNA, located mainly near the stop codons and the 3'-UTR $(55,58)$. Several studies have shown
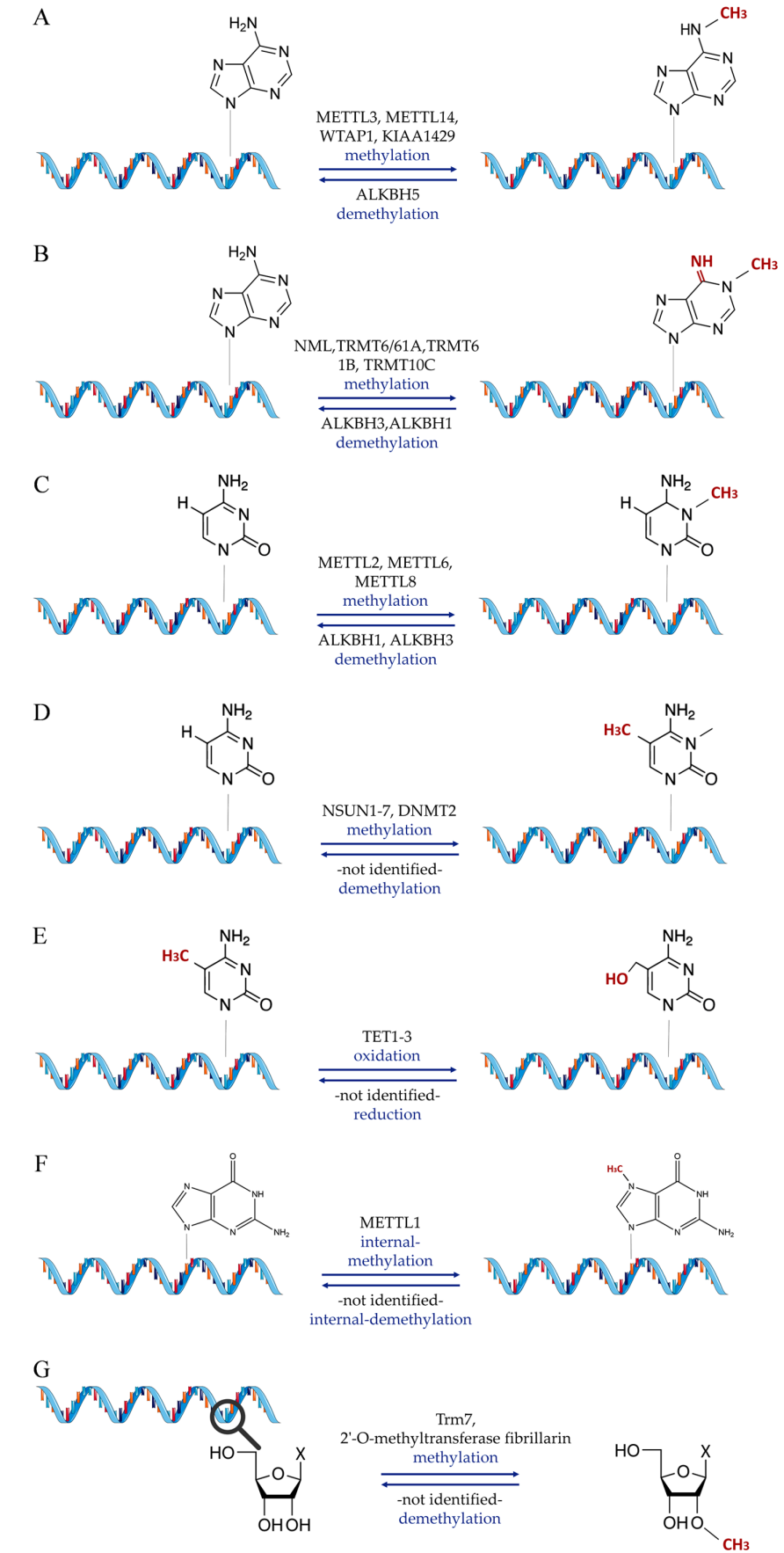

Figure 1. RNA methylation modifications along with their corresponding writers and erasers. (A) $\mathrm{m}^{6} \mathrm{~A}$ modification, (B) $\mathrm{m}^{1} \mathrm{~A}$ modification, (C) $\mathrm{m}^{3} \mathrm{C}$ modification, (D m ${ }^{5} \mathrm{C}$ modification, $(\mathrm{E}) \mathrm{hm}^{5} \mathrm{C}$ modification, $(\mathrm{F}) \mathrm{m} 7 \mathrm{G}$ modification and $(\mathrm{G}) \mathrm{Nm}$ (where $\mathrm{N}$ stands for any nucleotide) modification. $\mathrm{m}^{6} \mathrm{~A}, \mathrm{~N}^{6}$-methyladenosine; $\mathrm{m}^{1} \mathrm{~A}, \mathrm{~N}^{1}$-methyladenosine; $\mathrm{m}^{3} \mathrm{C}, 3$-methylcytosine; $\mathrm{m}^{5} \mathrm{C}, 5$-methylcytosine; $\mathrm{hm}^{5} \mathrm{C}, 5$-hydroxymethylcytosine; $\mathrm{m}^{7} \mathrm{G}, 7$-methylguanosine; Nm, 2'-O-methylation; METTL1/2/6/8/14, methyltransferase 1/2/6/8/14; WTAP1, Wilms tumor-associated protein-1; KIAA1429, vir like $\mathrm{m}^{6} \mathrm{~A}$ methyltransferase associated; ALKBH5, RNA demethylase ALKBH5; NML, nucleomethylin; TRMT6, tRNA methyltransferase 6 non-catalytic subunit; TRMT10C, tRNA methyltransferase 10 homolog C; ALKBH3, $\alpha$-ketoglutarate-dependent dioxygenase alkB homolog 3; ALKBH1, nucleic acid dioxygenase ALKBH1; NSUN, NOP2/SUN RNA methyltransferase; DNMT2, DNA methyltransferase-2; TET, methylcytosine dioxygenase; Trm7, tRNA [cytidine(32)/guanosine(34)-2'-O]-methyltransferase.

the importance of $\mathrm{m}^{6} \mathrm{~A}$ modifications in both mRNA and ncRNA stability (59), mRNA translation $(60,61)$, in secondary 
A

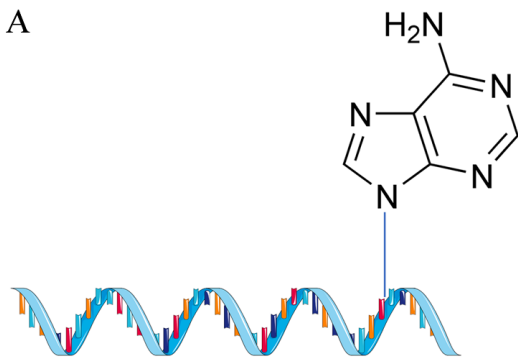

ADAR1/2

deamination<smiles>C=CCn1cnc2c(=O)[nH]cnc21</smiles>

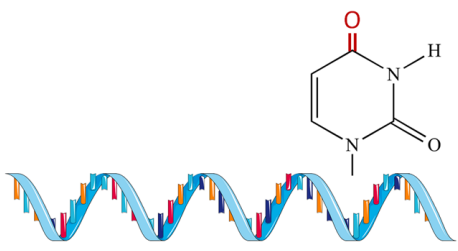

Figure 2. Substitutional RNA modifications and the two main mechanisms of RNA editing. (A) A-to-I editing and (B) C-to-U editing are presented. ADAR, adenosine deaminase acting on RNA; APOBEC1, apolipoprotein B mRNA editing enzyme catalytic subunit 1; APOBEC3A, apolipoprotein B mRNA editing enzyme catalytic polypeptide-like 3A.

A

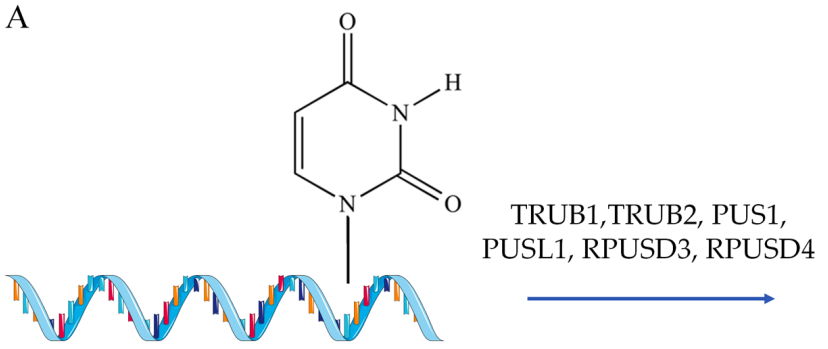

B<smiles>C=CCn1cnc2c(=O)[nH]c(N)nc21</smiles>

APOBEC1, APOBEC3A deamination

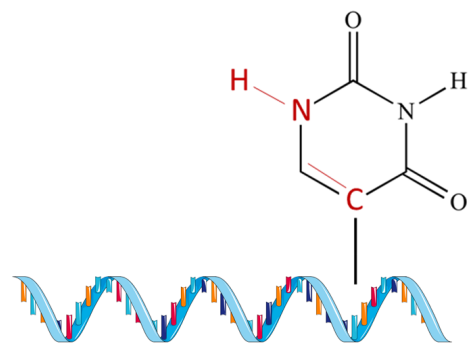<smiles>C=CC=CCn1c(=O)[nH]c2c(=O)[nH]c(N)nc21</smiles>

Figure 3. Other RNA modifications. Additional epitranscriptomic mechanisms that do not feature methylation or RNA editing, such as (A) pseudouridylation and (B) 8-OxoG modification. 8-OxoG, 8-oxoguanine; TRUB, TruB PUS family member; PUS1, pseudouridine synthase 1; PUSL1, pseudouridine synthase like 1; RPUSD, RNA pseudouridylate synthase domain; ROS, reactive oxygen species; OGG1, 8-oxoguanine glycosylase.

structure formation (mRNA and lncRNA) $(62,63)$, in polyadenylation (56,64-66), in circadian clock regulation (67), as well as in the response pathways to ultraviolet (UV)-induced DNA damage (68). The extent of $\mathrm{m}^{6} \mathrm{~A}$-modified RNA is both dynamic and reversible. $\mathrm{m}^{6} \mathrm{~A}$ modification is carried out and reversed by effector proteins, called $\mathrm{m}^{6} \mathrm{~A}$ writers and erasers (31). Writer proteins include methyltransferase 3 (METTL3) 3 and methyltransferase 14 (METTL14) (69,70), Wilms tumor-associated protein-1 (71) and vir like $\mathrm{m}^{6} \mathrm{~A}$ methyltransferase associated (72), which form a methyltransferase complex in mammals with its catalytic center located within METTL3 $(72,73)$, responsible for the deposition of $\mathrm{m}^{6} \mathrm{~A}$. Additional $\mathrm{m}^{6} \mathrm{~A}$ readers include YTH domain-containing family (YTHDF) proteins, such as YTHDF1, YTHDF2, YTHDF3 and YTHDC1, as well as heterogeneous nuclear ribonucleoproteins (HNRNPs), including heterogeneous nuclear ribonucleoproteins $\mathrm{C} 1 / \mathrm{C} 2$ (HNRNPC) (17). Conversely, for the reversal of $\mathrm{m}^{6} \mathrm{~A}$ modification, RNA demethylase ALKBH5, an RNA demethylase, acts as an activation and deactivation regulator (74).

$\mathrm{m}^{6} \mathrm{~A}$ modification is involved in various physiological and pathological aspects in the context of CVD, including cardiomyocyte remodeling, cardiac hypertrophy and regulation 
of mitogen-activated protein kinases (MAPKs). Since its extensive role in CVD has been thoroughly reviewed elsewhere $(17,18,75-77)$, we will only briefly mention some of the most prevalent findings, while updating information where necessary. Of heightened interest is the METTL3-mediated modification, which has been heavily implicated in cardiac function and homeostasis (78). METTL3 has been shown to be upregulated in mouse hearts following ischemia/reperfusion, acting in a negative feedback loop with transcription factor $\mathrm{EB}$, which controls the expression of autophagy and lysosomal genes (79-82). In failing hearts, $\mathrm{m}^{6} \mathrm{~A}$ hypermethylation of mRNA encoding for myosin regulatory light chain 2 led to lower protein levels compared with healthy controls (83). Overexpression of METTL3 led to a hypertrophic response both in vitro and in vivo, while cardiac-specific deletion of METTL3 caused signs of HF accompanied by functional and morphological changes (78). All of the above, indicate a central role for METTL3-mediated modification in cardiac homeostasis as well as the development of HF. During the development of HF, $\mathrm{m}^{6} \mathrm{~A}$ methylation has also been implicated in the regulation of calmodulin- 1 translation, a member of the calcium/calmodulin-dependent protein kinase II signaling pathway (84). Last, but not least, when examining obesity as a risk for the development of CVD, fat mass and obesity-associated protein (FTO), which was the first identified $\mathrm{m}^{6} \mathrm{~A}$ demethylase, appears to play a crucial role in obesity development, evidenced by the reduction effect on weight and adipose tissue after FTO knockdown (85). Aside from obesity, the FTO protein also appears to be decreased in the failing heart, leading to an increase in the content of $\mathrm{m}^{6} \mathrm{~A}$, in a state of hypoxia (86). By contrast, the correlation between the FTO protein and changes in calcium dynamics have been documented, resulting in changes of cardiomyocyte contraction and arrhythmic events (87). This serves to show that CVD can be influenced by $\mathrm{m}^{6} \mathrm{~A}$ modification events from a variety of sources or comorbidities, directly or indirectly related to its development, while this modification has also been shown to play a pivotal role in CVD-related risk factors, such as inflammation, obesity, insulin resistance and adipogenesis, whose disruption increases the risk of atherosclerosis (18).

$\mathrm{m}^{6} \mathrm{~A}$ methylation is also capable of influencing miRNA biogenesis and activity. Specifically, heterogeneous nuclear ribonucleoproteins $\mathrm{A} 2 / \mathrm{B} 1$, an $\mathrm{m}^{6} \mathrm{~A}$-binding protein, reads $\mathrm{m}^{6} \mathrm{~A}$ modifications in primary miRNAs (pri-miRs) and promotes DICER-mediated processing. This process affects miRNA-mRNA binding strength by influencing non-canonical base pairing (88). In angiogenesis, $\mathrm{m}^{6} \mathrm{~A}$ modification of the two vasoactive pri-miRNAs, pri-miR-126 and -222 by METTL14 and METTL3, respectively, accelerated their maturation, while it correlated with poor prognosis in patients with bladder cancer $(89,90)$. miRNA regulation has been extensively studied in the cardiovascular field and such miRNA epitranscriptomic events, further expand the complexity of the miRNA regulatory effects.

$\mathrm{m}^{6} \mathrm{~A}$ methylation has additionally been found to affect the stability of circRNAs and subsequently the circRNA-miRNA-mRNA network, activating the Wnt and FoxO pathways and promoting pulmonary hypertension $(91,92)$. X-inactive specific transcript (XIST), a lncRNA that is important in $\mathrm{X}$-chromosome inactivation during female development, has been shown to also act as a sponge for miR-101a-3p, promoting apoptosis during MI (93). Of note, XIST is highly methylated via two $\mathrm{m}^{6} \mathrm{~A}$ components, RNA binding motif protein 15 and RNA binding motif protein 15b (94). Metastasis associated lung adenocarcinoma transcript 1 (MALAT1), another lncRNA associated with cardiomyopathy and MI (95), was also found to contain a number of $\mathrm{m}^{6} \mathrm{~A}$ editing sites (96). Such modifications led to conformational changes and increased binding by a number of RNA binding proteins (RBPs) (97). In this context, a nuclear RBP that connects single-stranded poly- $U$ tracts and has a role in RNA processing and maturation is HNRNPC (63). This RBP is an $\mathrm{m}^{6} \mathrm{~A}$ switching factor and its binding capacity depends on the methylation of METTL3 or METTL14. This modification favors single-stranded RNA binding sites that are necessary for the interaction of HNRNPC with RNA molecules such as MALAT1 (63). Finally, another MALAT1 interacting protein is METTL16, a methyltransferase that adds $\mathrm{m}^{6} \mathrm{~A}$ to single-stranded U6 snRNAs (98). METTL16 is essential for embryonic development (99) and regulates the splicing of S-adenosylmethionine synthase isoform type-2, thus controlling the levels of methyltransferase substrate S-adenosyl methionine, as well as interacting with the $3{ }^{\prime}$ triple helix region of MALAT1, however the underlying mechanism of this process is not yet known $(98,100)$. In conclusion, it is evident that $\mathrm{m}^{6} \mathrm{~A}$ modifications have a vast array of effects in both coding and ncRNAs, while acting at multiple different levels of cardiac homeostasis and CVD development.

$m^{l} A$. The $\mathrm{m}^{1} \mathrm{~A}$ modification is one of the oldest detected RNA modifications, involving the methylation of the $\mathrm{N}^{1}$ site of the adenosine residue (101). Alongside 3-methylcytosine $\left(\mathrm{m}^{3} \mathrm{C}\right)$ and $\mathrm{m}^{7} \mathrm{G}$, it is the most common methylation modification encountered in physiological conditions (102). $\mathrm{m}^{1} \mathrm{~A}$ modifications are found in both mitochondrial and nuclear-encoded mRNAs, as well as rRNAs and tRNAs (103), catalyzed by a variety of enzymes, such as nucleomethylin in the case of rRNA methylation (104) or tRNA methyltransferase 6 non-catalytic subunit (TRMT6)/61 A, TRMT61B and TRMT10C for tRNAs (105-107). It reversibly methylates adenosine at positions 9, 14 and 58 of tRNA, while multiple sites exist within coding RNA transcripts and lncRNAs (108). The main erasers of $\mathrm{m}^{1} \mathrm{~A}$ modification are nucleic acid dioxygenase ALKBH1 (ALKBH1) and $\alpha$-ketoglutarate-dependent dioxygenase alkB homolog 3 (ALKBH3) (109). A study by Li et al (110) showed that the majority of the methylation sites in mitochondrial transcripts were found in either the 5'-UTR, where they increased transcription efficiency, or in the coding sequence region where they inhibited translation (110). Furthermore, a 3'-UTR site was also detected, leading to implications of potential miRNA specificity effects. Although no studies to date have directly correlated $\mathrm{m}^{1} \mathrm{~A}$ modifications with CVD, their impact on mitochondrial transcription cannot be overlooked. The heart is heavily reliant on mitochondria, due to its high energy demands. As such, dysregulated mitochondria have been associated with a number of cardiac diseases, including, among others, cardiac hypertrophy, HF and ischemia-reperfusion, as has already been reviewed elsewhere $(111,112)$. Of note, inferred $\mathrm{m}^{1} \mathrm{~A}$ methylation levels of mitochondrial-tRNA (mt-tRNA), as well as mt-RNR2 and mt-ND5 transcripts, have been observed 
in the cardiac left ventricle and the atrial appendage, as shown in a study by Ali et al (113). Nevertheless, further research is required to elucidate potential specific effects of $\mathrm{m}^{1} \mathrm{~A}$ editing events in the context of CVDs.

$m^{3} \mathrm{C} \cdot \mathrm{m}^{3} \mathrm{C}$ is a relatively under-investigated modification in CVD. Although it has been known as an RNA modification in yeast for some time, it was only recently detected in mammalian mRNA, in a study by Xu et al (114). Even though METTL2 and METTL6 are responsible for $\mathrm{m}^{3} \mathrm{C}$ modification of tRNA in mice and human (114), these only account for $\sim 50 \%$ of the total $\mathrm{m}^{3} \mathrm{C}$ tRNA methylation levels, suggesting a role for yet undiscovered methyltransferases. As far as mRNA $\mathrm{m}^{3} \mathrm{C}$ modification is concerned, METTL8 was shown to be the sole detected 'writer' enzyme (114). Some eraser enzymes that have been associated with this process are ALKBH1 and ALKBH3 $(115,116)$. Even though these methyltransferases have not been implicated in CVD, METTL2 has been shown to form a complex with DALR anticodon binding domain containing 3 (DALRD3) in humans, while a patient with a mutated DALRD3 exhibited mild congenital heart disease, which resolved spontaneously (117). Since $\mathrm{m}^{3} \mathrm{C}$ modifications are only now starting to garner attention, further research is required to identify their potential impact in CVD.

$m^{5} \mathrm{C}$. Cytosine $\mathrm{m}^{5} \mathrm{C}$, another common type of RNA modification, occurs in both mRNA and ncRNAs, such as tRNA, rRNA and lncRNA $(118,119)$. Research in both humans and mice has shown that the $\mathrm{m}^{5} \mathrm{C}$ sites are $\sim 100$ nucleotides downstream of the translation initiation site, as well as present in the UTRs $(120,121)$. Two main groups of $\mathrm{m}^{5} \mathrm{C}$ protein writers have been found. The first group consists of seven members of the NOP2/SUN RNA methyltransferase (NSUN) family (122) and includes methylate tRNA (NSUN2, NSUN6), rRNAs (NSUN1, NSUN5), mRNAs (NSUN2), ncRNAs (NSUN2), mt-rRNAs (NSUN4) and mt-tRNA (NSUN3) (122-128). The second group comprises only DNA methyltransferase-2 (DNMT2) (129), previously speculated to be DNA specific, but has previously been found to also act on tRNA (130). Although, to date, eraser proteins of $\mathrm{m}^{5} \mathrm{C}$ modifications have not been identified, a previous study suggested a role for $\mathrm{m}^{5} \mathrm{C}$ in RNA transport (118). The Aly/REF export factor, an mRNA export adaptor protein identified as $\mathrm{m}^{5} \mathrm{C}$ binding (reader) protein, is involved in this process (118).

Notably, mutations in both $\mathrm{m}^{5} \mathrm{C}$ writer groups have been associated with adverse effects in various diseases, such as cancer and intellectual disability (131-134). According to an in vitro study, where the DNMT2 gene was examined, a total of $>60$ somatic mutations have been identified, with variable DNMT2 methylation activity (135). Mice lacking the NSUN4 gene, a mitochondrial $\mathrm{m}^{5} \mathrm{C}$ methyltransferase, did not survive birth, while NSUN4 cardiac conditional deletion resulted in mitochondrial dysfunction and cardiomyopathy (126). DNMT2-deficient mice have also been shown to develop cardiac hypertrophy, possibly via the dysregulation of the interaction between positive transcription elongation factor b (P-Tefb), a transcription regulator, and RNA component of 7SK nuclear ribonucleoprotein (Rn7sk), a ncRNA (136). Decreased levels of $\mathrm{m}^{5} \mathrm{C}$ methylation in DNMT2-deficient hearts suggested disruption of P-Tefb/Rn7sk association (136).
Luo et al (137) were able to show, both in vitro and in vivo, that NSUN2-mediated methylation of intercellular adhesion molecule 1 increased vascular inflammation, while its knockdown led to the development of atherosclerosis (137). In an atherosclerotic plaque mice study, increased IL-17A translation was observed as a result of $\mathrm{m}^{5} \mathrm{C}$ methylation of the IL-17A mRNA coding region (138).

In regards to $\mathrm{m}^{5} \mathrm{C}$ methylation of ncRNAs a study by Yuan et al (139) showed that $\mathrm{m}^{5} \mathrm{C}$ editing was present during miR-125b biogenesis, a miRNA also heavily implicated in atherosclerosis $(140,141)$. NSUN2-mediated methylation inhibited the function of miR125b, by repressing its processing in all maturation stages, including pri-miR, precursor miRNA (pre-miR) and mature miRNA both in vitro and in vivo (139). The previous findings regarding $\mathrm{m}^{5} \mathrm{C}$ editing events of coding RNAs, imply extensive roles for $\mathrm{m}^{5} \mathrm{C}$ methylation in multiple levels of the complex atherosclerosis network $(137,142)$. Antisense ncRNA in the cyclin-dependent kinase inhibitors (INK4) locus (ANRIL), a lncRNA which has been previously identified in patients with MI as a poor prognostic marker for cardiac function, has also been shown to undergo $\mathrm{m}^{5} \mathrm{C}$ modification, although the extent of this IncRNAs influence in cardiac function remains unknown $(47,121)$. The pathophysiological conditions resulting from the deregulation of the system of $\mathrm{m}^{5} \mathrm{C}$ modifications demonstrate the importance of these modifications in controlling the fate and function of RNAs (143).

$h m^{5} C$. Although the epigenetic importance of $\mathrm{hm}^{5} \mathrm{C}$ DNA modification in mammals has long been established, the potential of such an editing event in RNA remains unclear. In a study by Fu et al (144), it was found that the same family of enzymes that catalyzes this modification in DNA, the ten-eleven translocation family, was able to catalyze the formation of 5-hydroxymethylcytosine (5-hmrC) in RNA in vitro and in vivo (144). They also determined that the ratio of conversion from 5 -mrC to 5 -hmrC was roughly $0.02 \%$. Of note, out of all the tissue types tested, the highest levels of $5-\mathrm{hmrC}$ were detected in the cardiac tissue, with 3.9 modifications per $10^{6}$ ribonucleotides (144). Even though the relative levels of this modification in RNA are lower than in DNA, it is still unknown whether this is a stable or transient oxidation effect. Furthermore, in a study by Fang et al (145), it was observed that cardiac-specific deletion of methylcytosine dioxygenase TET2 and TET3 had adverse effects on DNA hydroxymethylation dynamics during embryonic heart development, while leading to a reduction in cardiomyocyte numbers and the emergence of non-compaction cardiomyopathy. In light of the aforementioned studies, it would be of interest to investigate the effects of cardiac deletion of TET family genes in RNA hydroxymethylation dynamics.

$m^{7} G \cdot \mathrm{m}^{7} \mathrm{G}$, one of the most conserved modifications of nucleosides that make up eukaryotic mRNA, plays an essential role in regulating protein synthesis, pre-mRNA splicing and the export of mRNA (146). $\mathrm{m}^{7} \mathrm{G}$ is additionally present at defined internal positions, within other classes of RNAs, such as tRNAs and rRNAs (147). One of the most extensively described enzymes that mediate internal $\mathrm{m}^{7} \mathrm{G}$ methylation, METTL1, has been shown to mediate $\mathrm{m}^{7} \mathrm{G}$ modification in miRNAs (148). More 
specifically, it has been documented that METTL1-mediated methylation led to an increase in lethal-7 (let-7) miRNA processing (148). The family of let-7 miRNAs has been extensively studied in various diseases and participates in regulating cell differentiation $(149,150)$. Members of this miRNA family have been implicated in CVD, as evidenced by a study in which the inhibition of let-7c miRNA was shown to prevent the deterioration of cardiac infarction, in vitro and in vivo (151). A study by Yang et al (152), which focused on angiotensin II-treated hearts and isolated cardiomyocytes, reported upregulation of several let-7 miRNA members, indicating their possible role in cardiac hypertrophy, while let-7i expression was downregulated in patients with dilated cardiomyopathy and correlated with poor clinical outcomes (153). The effects of $\mathrm{m}^{7} \mathrm{G}$ modification in the context of CVD thus remain largely unexplored, but the implications of let-7-mediated effects hint to regulatory levels of potentially high importance.

$\mathrm{Nm}$. Nm ( $\mathrm{N}$ meaning any nucleotide in this case) is a modification of RNA occurring co-transcriptionally or post-transcriptionally, where a methyl group is added to the 2'-hydroxyl of the ribose moiety (154). This type of modification is recurrent and observed in numerous RNA classes, such as sncRNAs, mRNA and tRNA (154). This modification can be carried out by stand-alone methyltransferases (155), such as tRNA [cytidine(32)/guanosine(34)-2'-O]-methyltransferase or by the fibrillarin enzyme, which requires guiding by box $\mathrm{C} / \mathrm{D}$ snoRNAs (156). Loss of snoRNA-guided Nm modifications on snRNAs reportedly leads to significant defects in the splicing of cardiac mRNA and the development of the heart $(157,158)$. In cardiometabolic disease, small nucleolar RNA C/D Box 32A, a subtype of ncRNA from the Rpl13a locus, was found to target the mRNA of peroxidasin for $\mathrm{Nm}$, indicating a role in the functional altering of peroxidase activity in the heart (159). As in the case of $\mathrm{m}^{7} \mathrm{G}$ modifications, research in this modification area is still limited, but cardiovascular effect implications exist, capable of driving future research avenues.

\section{Substitution modifications}

A-to-I editing. A-to-I RNA editing is the most common form of substitutional RNA editing in mammals (160). During this process, two conserved mammalian enzymes, adenosine deaminase acting on RNA (ADAR)1 and 2, hydrolyze the adenosine residues into double-stranded RNA regions (mRNAs and ncRNAs) in order to convert them into inosines (161). Due to the similar chemical content inosines share with guanines, they are misread by the endogenous translational complex during reverse transcription and thus pair with cytosines (162). A-to-I editing has been shown to be indispensable both for physiological development and the emergence of pathological conditions in the heart, while an average of $\sim 80,000$ A-to-I editing sites have been identified in human cardiac tissue (163).

ADAR1 has been shown to edit cathepsin S (CTSS), a cysteine protease associated with atherosclerosis and angiogenesis (164-166). The editing event occurred in the 3'-UTR region of CTSS mRNA, enabling the recruitment of ELAV like RNA binding protein 1 , which in turn regulated the mRNA expression and stability of CTSS. Of note, both ADAR1-mediated editing and CTSS mRNA expression were elevated in blood samples from patients with coronary artery disease (167). In mice, ADAR1 was increased during oxidative stress in neonatal cardiomyocytes (168), while a knockout study in the developing heart showed that ADAR1 cardiac deletion is associated with embryonic lethality, establishing the importance of A-to-I RNA editing during cardiac embryonic development for both proliferation and survival (169). Additionally, El Azzouzi et al (170) were able to bypass embryonic lethality and knock out ADAR1 in adult cardiomyocytes by using an inducible knockout method under the control of the $\alpha$-myosin heavy chain promoter, which is specifically expressed in cardiomyocytes. Their results showed increased lethality in Adar1-null mice, accompanied by a decrease in global miRNA expression, worsening of cardiac function and severe ventricular remodeling, via a pathway involving miR-199a-5p and the unfolded protein response (170). In a study by van der Kwast et al (44), an edited version of miR-478b-3p, a miRNA present in smooth muscle cells, fibroblasts and vascular endothelial cells, was responsible for neovascularization in response to ischemia. The A-to-I modification of miR-478b-3p was located in the seed sequence and modified its target set by enriching for proangiogenic pathways (44). Moreover, Filamin A (FLNA) mRNA has been previously shown to be one of the substrates for ADAR2 editing (171). In a study by Jain et al (172), mice with impaired FLNA editing developed left ventricular hypertrophy and cardiac remodeling, accompanied by elevated blood pressure. Additionally, FLNA mRNA editing in patients with CVD was found to be decreased by up to 50\%, making ADAR2-mediated FLNA mRNA editing one of the first studies to highlight an editing event associated with cardiac disease in humans (172). In terms of occurrence, there is limited information about A-to-I modifications in lncRNAs. Nevertheless, ANRIL, a lncRNA acting as a regulator of coronary heart disease, was shown to undergo A-to-I editing at the site of its Alu motifs, potentially affecting its interaction with chromatin and its downstream effects (47).

$C$-to- $U$ editing. C-to- $\mathrm{U}$ editing is another editing mechanism acting in mammals $(173,174)$. It is regulated by a family of evolutionarily conserved cytidine deaminases called APOBEC, in a highly specific manner with a preference for cytidines in AU-rich regions (175). First observed regulating the expression of apolipoprotein-B48 in a tissue-dependent manner, C-to-U modification in the liver produces a truncated apolipoprotein, via the introduction of a stop codon in the gene transcript, resulting in the hepatic-specific apolipoprotein-B100 expression (176). The APOBEC1 complementation factor (ACF), an RNA-binding cofactor, integral in editing apolipoprotein $\mathrm{B}$ is one of the two minimal elements for a functional C-to-U editing complex $(177,178)$. Of note, CUGBP Elav-like family member (CELF)2, another RBP that has been shown to also modulate C-to-U editing by recruiting ACF (179), is mainly expressed in the heart, alongside another member of the CELF family, CELF1 (180). The activity of CELF1 ranges from RNA editing to polyadenylation and alternative splicing, while CELF1 depletion can cause neonatal cardiac dysfunction with repression effects in ion-transport and circadian gene expression (181).

Although the activity of APOBEC1 is responsible for editing apolipoprotein $\mathrm{B}$, it has been previously reported that 
another member of the subfamily, APOBEC2, is exclusively expressed in the heart and skeletal muscle, and maintains low, but definite deaminase activity (182). Meanwhile, APOBEC3A is capable of C-to-U editing under hypoxic conditions (183), while its overexpression induced editing, among others, of primary pulmonary hypertension genes in an in vitro experiment (184). All of the above imply a yet undiscovered potential for RNA editing of cardiac-specific transcripts in a C-to-U editing manner, similar to the one observed for apolipoprotein modifications in the liver.

\section{Other modifications}

$\Psi$. 5-Ribosyluracil/ $\Psi$, an isomer of the conventional RNA nucleoside uridine (185) is overall the most common RNA modification. It has been found in mRNA, as well as tRNA, rRNA, snRNA, snoRNA and ncRNA (186). This modification is observed in almost all tRNA molecules, as the TUC loop is characteristic of tRNAs (187). One of the $\Psi$ functions is to enhance the ability of RNA to stack bases by making the sugar-phosphate backbone more rigid $(188,189)$. Additionally, it participates in the classic Watson-Crick base coupling with adenosine, such as unmodified uridine isomer, but presents a stronger pairing with the other four bases (190). A total of 13 pseudouridine synthases (PUS) have been identified in humans, acting both in an RNA dependent and independent manner (191).

In a previous study by Safra et al (192), a member of the TruB PUS family member 1 (TRUB1) family, also known as PUS4 and PUS7, was shown to combine $\sim 60 \%$ of all reproducible $\Psi$ detected sites in mRNA in three human cell datasets. These datasets consisted of fibroblasts and HEK293 cells, HeLa cells grown under wild-type or serum-starved conditions and HEK293 cells grown under a range of conditions/perturbations, respectively. A consensus motif (GUUCNANNC) for $\Psi$ by TRUB1 has been identified, while its catalytic activity is mainly located in the nucleus (192). It is worth noting that several other PUS, such as PUS1, pseudouridine synthase-like 1, TRUB2, RNA pseudouridine synthase domain containing 3 (RPUSD3) and RPUSD4, have been predicted or found to be mitochondrial RNAs (mtRNAs), resulting in a number of mtRNAs being modified by PUS enzymes $(193,194)$.

As in the previous modifications, the mutations in PUS are related to various diseases, such as cancer and mitochondrial myopathy $(195,196)$. Of note, the absence of eraser proteins for the $\Psi$ modifications, coupled with the inactivity of the $\mathrm{C}-\mathrm{C}$ bond between the base and the sugar $(\Psi)$, suggest that this is a potentially irreversible modification (188). Analysis of TRUB1 levels in human tissue revealed its high expression in the heart and skeletal muscle, with still unexplored modification potential mainly in tRNAs (197). Moreover, during both $\Psi$ and $\mathrm{Nm}$ methylation modifications, snoRNAs have been found to act as guides for the modification process $(159,198)$. A special class of guide RNAs concentrated in the Cajal body are responsible for guiding spliceosomal $\mathrm{U}$ modifications, these snRNAs are termed scaRNAs (199). In this regard, scaRNAs are responsible for regulated alternative splicing, with extensive implications for response to variable environmental conditions (158). Notably, in a study by Nagasawa et al (200), infants born with a common congenital cardiac defect termed Tetralogy of Fallot, were shown to have decreased spliceosomal pseudouridylation levels in their right ventricle, which in turn depended on scaRNA1 levels, as exhibited in an in vitro experiment in primary cardiomyocytes (200). These findings imply that spliceosomal pseudouridylation depends on scaRNA levels in human tissue, revealing a novel potential regulatory mechanism for the alternative splicing of genes important in embryogenesis and cardiogenesis. KCNQ1 overlapping transcript 1 , a lncRNA and a biomarker for MI, has also been shown to be able to be modified by $\Psi$ (201). Establishing studies with a larger number of samples and the examination of additional RNA modifications and epigenetic factors is necessary for deeper investigation into the cardiovascular effects of pseudouridylation.

8-OxoG. Finally, 8-OxoG is conventionally formed through the interaction of the guanine base in DNA molecules with reactive oxygen species, under conditions of oxidative stress (202). Repair of this type of base lesion is executed by the enzyme 8-OxoG glycosylase (OGG1), which excises 8-OxoG (203). A study by Shah et al (204) documented the detrimental effects of 8-OxoG on the function of vascular smooth cells, reporting a reduction of human atherosclerotic plaque development when the activity of 8-OxoG glycosylase was restored. By sequencing oxidized miRNAs in rat models, 8 -OxoG modifications at specific positions in miR-1 were found to promote cardiac hypertrophy (205). Additionally, 8-OxoG DNA glycosylase 1 overexpression was found to lower cardiac mitochondrial levels of DNA 7,8-dihydro-8-OxoG (8-oxo-dG) in mouse models (206). The same study evidenced the decrease in transverse aortic constriction-induced cardiac fibrosis in a state of OGG1 overexpression, suggesting that increased repair of 8-oxo-dG in mtDNA leads to decreased cardiac pathology (206). In a study by Noren Hooten et al (207), 8-oxo-dG levels were found to be associated with clinical cardiovascular risk factors, such as high sensitivity C-reactive protein, systolic blood pressure, IL-23 levels and body/mass index. Moreover, strong association between 8-oxo-dG and the levels of systolic blood pressure have been documented (207). Although there are implications for important regulatory effects mediated by 8-oxo-dG modification in the cardiac tissue, this field of research remains in its infancy.

\section{Tools of epitranscriptomic modification research}

In the past decade, dramatic advances in the development of powerful sequencing technologies have facilitated transcriptomic investigation in a faster, more efficient and more in-depth manner than ever before. Such advances have also assisted greatly in the study of epigenetics and epitranscriptomics. The use of RNases constitutes one of the earliest methods of mapping mRNA modifications and still exhibits the highest sensitivity for $\mathrm{m}^{6} \mathrm{~A}$ mapping (208). In the same manner, the more recent MAZTER-seq (209) and $\mathrm{m}^{6} \mathrm{~A}-\mathrm{REF}-\mathrm{seq}$ (210) technologies exploit the discovery of methylation-blocked endoRNases. Another method, termed site-specific cleavage and radioactive-labeling followed by ligation-assisted extraction and thin-layer chromatography, also known as SCARLET, utilizes site-specific cleavage and splint ligation and has also been extensively used to detect $\mathrm{m}^{6} \mathrm{~A}$ modifications in both 
coding RNA and lncRNAs (211). Furthermore, antibody incorporating techniques have been established for the detection of RNA modifications. These include the $\mathrm{m}^{6} \mathrm{~A}-\mathrm{LAIC}$-seq or $\mathrm{m}^{6} \mathrm{~A}$-level and isoform-characterization sequencing method, which uses immunoprecipitation in total RNA samples (56), as well as the widely used MeRIP-Seq technology, which maps $\mathrm{m}^{6} \mathrm{~A}$-methylated RNA through the use of $\mathrm{m}^{6} \mathrm{~A}$-specific antibodies (212). Combining the aforementioned technique with Ab cross-linking, allowed the enhancement of the resolution of the technique, giving rise to methylation individual-nucleotide resolution UV cross-linking and immunoprecipitation (124). Applications of the same principle of cross-linking include PA-m ${ }^{6} \mathrm{~A}$-seq (213), but also $\mathrm{m}^{1} \mathrm{~A}-\mathrm{MAP}(110)$ in the case of $\mathrm{m}^{1} \mathrm{~A}$ modification mapping.

Alternative methods for the detection of RNA modifications take advantage of chemical reactions that are limited to a certain type of RNA modification, combining them with short-read sequencing. RNA-BisSeq, aimed toward the mapping of $\mathrm{m}^{5} \mathrm{C}$, involves the chemical deamination of cytidines except for $\mathrm{m}^{5} \mathrm{C}$ (118). Modern library preparation protocols, yield RNA fragments with nucleotide modifications at the 5'- or 3'-end, which can be used for the enrichment of the RNA fragments in RNA seq libraries $(214,215)$. The Nm-Seq and RibOxi-Seq techniques used to map internal Nm modifications entail the treatment of RNA fragments with $\mathrm{NaIO}_{4}$ oxidation, which along with additional steps, leads to the enrichment of 3'-Nm-containing fragments and improvement of the final transcriptome-wide RNA analysis $(166,216)$. Using the same principle, RiboMethSeq is based on the protection of the phosphodiester bond in RNA when Nm occurs at the 5'-neighboring ribose (217). Following alkaline hydrolysis, library preparation and 5'- and 3'-extremity counting, the aforementioned protection is translated into a signal.

Mass spectrometry (MS) has also been an invaluable tool for RNA modification analysis. State-of-the-art MS methods are being employed for the detection and quantification of chemical modifications in RNA, yielding different types of information based on the type of MS analysis (218). Top-down MS analysis can identify and localize mass-altering RNA modifications in undigested RNA, while also allowing de novo sequencing to be performed. Nevertheless, non-altering mass modifications, such as $\mathrm{m}^{1} \mathrm{~A}, \mathrm{~m}^{6} \mathrm{~A}$ and mass-silent modifications, such as pseudouridine, remain a major challenge $(219,220)$. Bottom-up MS is conducted for the mass mapping of partially hydrolyzed RNA, and MS approaches can generate oligonucleotides and sequencing ladders that can be subsequently interpreted into RNA sequences and localization of the modifications (221). Another MS-based method is nucleoside MS, which is performed on complete RNA hydrolysates, followed by liquid chromatography separation of the nucleoside mixtures. While highly accurate for the detection of chemical modifications, it cannot provide sequence information or localization of the modification (222). Still, each method's advantages can be combined to overcome limitations and drawbacks on high-throughput RNA modification mapping, while appropriate software for MS data processing should always be incorporated (223).

A-to-I modifications are either investigated via the traditional method of screening for A-to-G mismatches in reverse transcribed RNAs (224), by the use of the more recently developed inosine chemical erasing (ICE) methods, or by the use of transgenic mice where ADAR knockdown is followed by deep-sequencing. In the case of ICE, reverse transcription is blocked by the formation of $\mathrm{N}^{1}$-cyanoethylinosine after acrylonitrile processing. This method combined with deep-sequencing gave rise to ICE-seq, for high-throughput investigation of A-to-I modifications (225). In the case of $\Psi$ modification profiling, several high-throughput sequencing techniques are utilized, wherein treatment with $\mathrm{N}$-cyclohe xylN'-(2-morpholinoethyl)-carbodiimide-metho-p-toluenesulfonate specifically modifies $\Psi, G$ and $U$ residues on RNA. Although the $\mathrm{G}$ and $\mathrm{U}$ modifications are later removed, the chemically induced modification on $\Psi$ is stable and blocks reverse transcription (226). Such methods include $\Psi$-seq (227), PSI-seq (228), Pseudo-seq (229) and CeU-seq (230).

Novel sequencing approaches enable direct RNA sequencing without amplification or cDNA conversion. The rapidly developing technology of nanopore sequencers, such as the one created by Oxford Nanopore Technologies (ONT), includes the use of a synthetic membrane with embedded nanopores in an ionic solution (231). As an ionic current passes through the nanopore, an individual read is recorded by a sensor and the corresponding data is acquired by the sequencer's implemented software. Characteristic changes in the current reads during the movement of a nucleic acid strand, as it traverses the nanopore from one chamber to the other, enable the identification of the strand's nucleic acid sequence, in a process known as 'base-calling' (232). Nucleotide modifications in ONT reads can be determined with the use of specialized software, such as Nanopolish and the ONT integrated CpG-methylation calling software (233).

\section{Epitranscriptomic genetic variation and CVD}

High-throughput sequencing techniques have not only promoted the field of epitranscriptomic profiling, but have, through Genome-wide Association Studies (GWAS), facilitated the identification of single nucleotide polymorphisms (SNPs) in a variety of diseases, including CVD (234). These studies have led to the identification of $>5,000$ associations with CVD (https://www.ebi.ac.uk/gwas/) (235), exhibiting the importance of SNPs in CVD emergence. Several databases have also been developed in an effort to catalogue disease-associated polymorphisms that affect epitranscriptomic modifications. These databases include $\mathrm{m}^{6}$ Avar (236) and $\mathrm{m}^{6} \mathrm{ASNP}$ (237), both of which catalogue $\mathrm{m}^{6} \mathrm{~A}$-related polymorphisms, $\mathrm{m}^{7} \mathrm{GHub}$ (238) focusing on $\mathrm{m}^{7} \mathrm{G}$-related SNPs, RMDisease encompassing $>200,000$ human SNPs that affect $\mathrm{m}^{6} \mathrm{~A}, \mathrm{~m}^{1} \mathrm{~A}, \mathrm{~m}^{6} \mathrm{Am}, \mathrm{m}^{5} \mathrm{U}$, $\mathrm{m}^{7} \mathrm{G}, \Psi$ and Nm modifications (239) and the RNA Framework, which is a rounded toolkit for the analysis of post-transcriptional modifications (240).

In terms of epitranscriptomic genetic variation, research remains at an early stage. As expected due to the greater emphasis given so far on $\mathrm{m}^{6} \mathrm{~A}$-related modifications, in the context of CVD, a number of $\mathrm{m}^{6} \mathrm{~A}$-related SNPs have been recognized as genetic variants associated with CVD. Multiple GWAS studies by Mo et al (241) have paved the way in this field and associated $\mathrm{m}^{6} \mathrm{~A}-\mathrm{SNPs}$ with a variety of CVD factors. More specifically, $\mathrm{m}^{6} \mathrm{~A}-\mathrm{SNPs}$ were shown to be associated with coronary artery disease (241) and have a potential role 
in the regulation of blood pressure (242), as well as in the regulation of lipid metabolism (243). Furthermore, several $\mathrm{m}^{6} \mathrm{~A}$-related SNPs were found to affect the expression of multiple disease-causing genes, with potential adverse effects for ischemic stroke in humans (244). In this context, the genetic variant rs12286, which is strongly associated with coronary artery disease, was shown to be able to affect ADAMTS7 expression, by regulating the upstream $\mathrm{m}^{6} \mathrm{~A}$ methylation (241). Ali et al (113) analyzed the levels of $\mathrm{m}^{1} \mathrm{~A} / \mathrm{G}$ methylation in mitochondrial-encoded RNA across multiple tissue types, followed by the identification of overlaps between peak associated nuclear variants and disease-associated variants with significance on a genome-wide level. Nuclear genetic variants (rs13874, rs1084535), which are associated with inferred methylation levels at mt-RNR2 and several mt-tRNA P9 sites, were in linkage disequilibrium (LD) with rs34080181, which has been linked to atrial fibrillation (245). Furthermore, the intronic variant in polyribonucleotide nucleotidyltransferase 1 mitochondrial (rs2627773) that is associated with inferred methylation levels of mt-RNR2, is in LD with rs1975487, which is associated with diastolic pressure (246). Franzén et al (247) mapped A-to-I RNA editing quantitative trait loci (edQTLs) in order to identify clinical features associated with RNA editing. Subsequently, they evaluated the disease relevance of RNA editing by intersecting the edQTLs with GWAS data (247). More specifically, the authors intersected edSNPs with lead SNPs from published GWAS data. Of note, the rs10847434 SNP, which is associated with coronary artery disease (248) had an edQTL with an editing site in the 3 ' exon of apolipoprotein $\mathrm{Cl}$ pseudogene 1, a locus that has been linked to coronary artery disease (249). Additionally, the SNP rs4739066, a polymorphism associated with MI (250), was also found to have two edQTLs with editing sites in the 3'-UTR of the $\alpha$-tocopherol transfer protein gene, a gene associated with the level of severity of atherosclerotic lesions in the area of the proximal aorta (251). Taken together, the aforementioned studies suggest that there is still a large unexplored area of genetic variation related to CVD pathogenesis, especially in regards to epitranscriptomic modifications.

\section{Therapeutic implications of epitranscriptomics in CVD}

Although the field of epitranscriptomics is still in its infancy, there are already efforts being made to utilize such new regulatory knowledge for the development of novel therapeutic approaches, both for epigenetic and epitranscriptomic modifications in the context of CVD (19). As previously discussed, most epitranscriptomic research in CVD has so far been focused on $\mathrm{m}^{6} \mathrm{~A}$ modifications and, as such, methods have focused on identifying ways to manipulate $\mathrm{m}^{6} \mathrm{~A}$ methylation levels in the context of various therapeutic approaches. In a seminal study by Lu et al (252), it was established that curcumin was able to attenuate the effects of lipid metabolism disorder and increase total cholesterol in the liver, via the increase of $\mathrm{m}^{6} \mathrm{~A}$ methylation, suggesting a protective role for this modification against hyperlipidemia. Recently, a large scale epitranscriptomic study has been established to identify IHD biomarkers in circulation, termed the IHD-EPITRAN study. This study is expected to include 200 patients, split into two cohorts of IHD and non-IHD patients, focusing on the identification of $\mathrm{m}^{6} \mathrm{~A}$ and
A-to-I modification biomarkers (253). Additionally, limited approaches have also been taken in an effort to modulate $\mathrm{m}^{6} \mathrm{~A}$ demethylation. Inhibition of demethylation was selectively blocked by the use of meclofenamic acid (MA) in vitro (254), while using the recently developed CRISPR-Cas13b technology, Li et al (255) attempted to manipulate $\mathrm{m}^{6} \mathrm{~A}$ modified transcripts and specifically demethylate $\mathrm{m}^{6} \mathrm{~A}$ marks. In a similar manner, Cox et al (256) developed the RNA Editing for Programmable A to I Replacement system, also utilizing CRISPR-Cas13b technology, to address disease-causing mutations. Although such tools are still outside the reach of clinical practice, as multiple technical and ethical concerns remain unaddressed, they pave the way for the development of future personalized CVD therapeutics.

\section{Conclusions}

The field of epitranscriptomics has been rapidly emerging, as the focus regarding disease development, environmental adaptation and homeostasis maintenance, shifts from the rigid genomic structure to the much more dynamic transcriptomic landscape. Although there have been major advances in transcriptomic profiling, understanding the mechanisms in which the transcriptome itself is differentially regulated through modifications, will allow for the development of novel and precise pharmacological interventions. The additional level of regulatory sensitivity that epitranscriptomic modifications are shown to offer, corresponds to the increased level of specificity required for any successful therapeutic intervention. To date, epitranscriptomic modifications are nearing 200, but not all of them have been thoroughly evaluated, nor do they all appear with equal frequency. Although epitranscriptomic research progresses rapidly in the fields of cancer and neurodegenerative disorders $(257,258)$, in the context of CVD the number of modifications that have a significant impact are just beginning to be elucidated (Table I). However, their biological and clinical significance cannot be denied, as shown by the plethora of studies published in the past couple of years, showing the effect of RNA modifications in CVDs (Fig. 4).

Regarding RNA methylations, undoubtedly $\mathrm{m}^{6} \mathrm{~A}$ has garnered the most attention. Although coding RNA modifications have been the focus of most $\mathrm{m}^{6} \mathrm{~A}$ studies in the heart, a number of publications have emerged, pinpointing the importance of various RNA methylations in multiple levels of non-coding regulation in the heart. These events occur in multiple miRNA maturation stages, including primary-miRNA, pre-miR and mature miRNA levels. Coupled with recently emerging implications regarding methylation modifications in circRNAs and lncRNAs, such as XIST, in the context of CVD, it is becoming evident that this type of epitranscriptomic modification is paramount for physiological non-coding regulation and offers an additional regulatory level of gene expression, sensitive to environmental factors. Nevertheless, methylations are only one of the available modifications in the RNA modification toolset. Substitutional modifications have also been gaining attention in the cardiovascular field, especially with the emergence of recent studies exhibiting the importance of ADAR1 for cardiac development, homeostasis, as well as physiological cardiac function in adult mice $(169,170,259)$. What is noteworthy is that the ADAR1-mediated modification, 
RNA methylation modifications

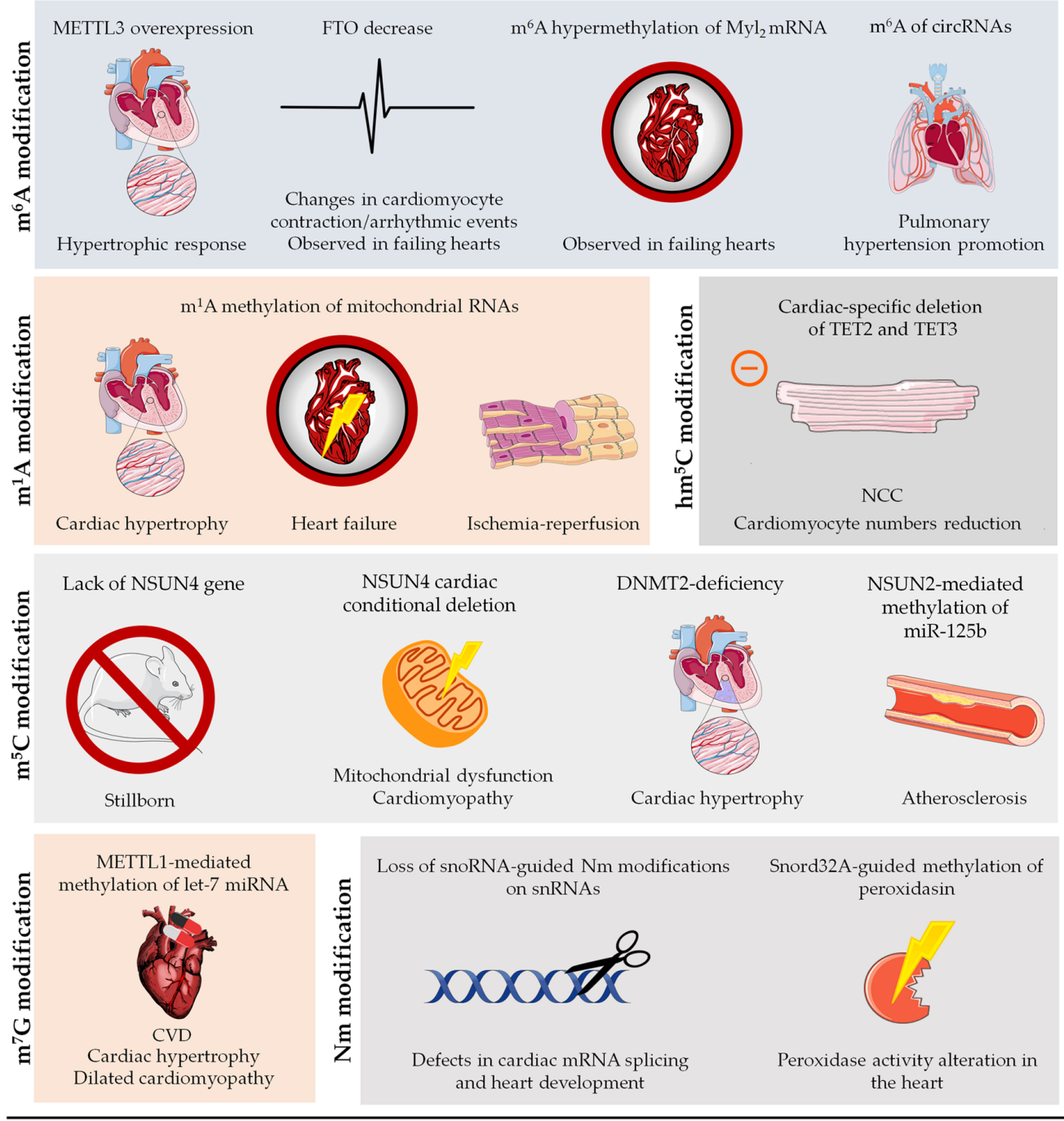

\section{Substitutional RNA modifications}

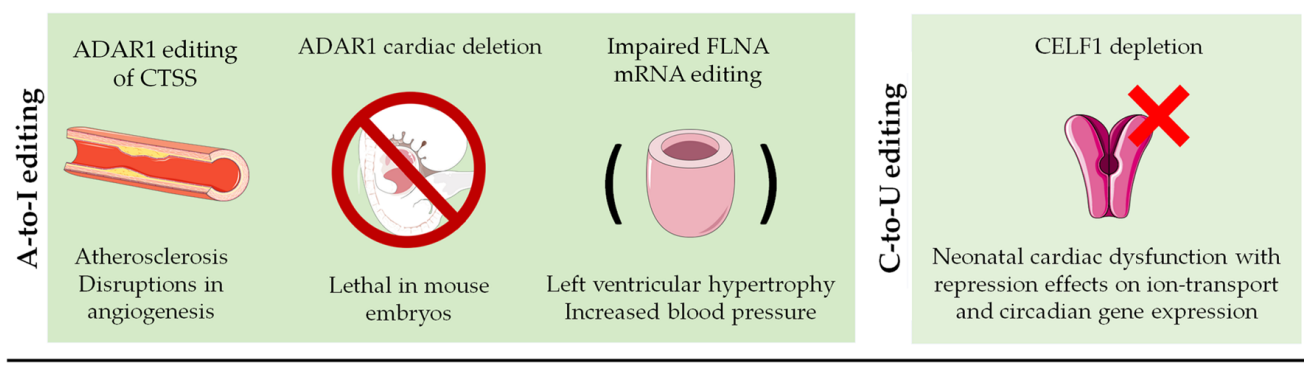

\section{Other RNA modifications}
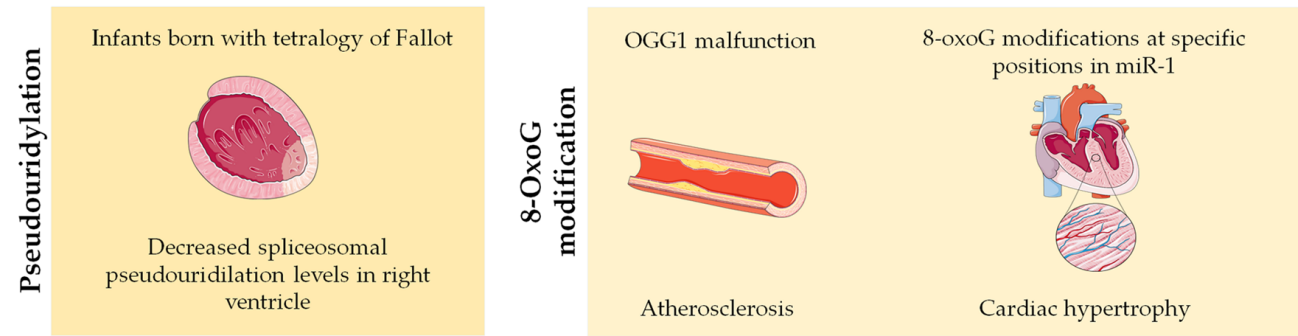

Figure 4. Schematic representation of RNA modifications and their role in CVDs. CVD, cardiovascular disease; METTL3, methyltransferase 3; FTO, fat mass and obesity-associated protein; $\mathrm{m}^{6} \mathrm{~A}$, N6-methyladenosine; Myl2, myosin regulatory light chain 2 ventricular/cardiac muscle isoform; circRNAs, circular RNAs; $\mathrm{m}^{1} \mathrm{~A}, \mathrm{~N}^{1}$-methyladenosine; TET, methylcytosine dioxygenase; NCC, non-compaction cardiomyopathy; $\mathrm{m}^{5} \mathrm{C}, 5$-methylcytosine; NSUN4, NOP2/SUN RNA methyltransferase 4; DNMT2, DNA methyltransferase-2; NSUN2, NOP2/SUN RNA methyltransferase 2; miR/miRNA, microRNA; METTL1, methyltransferase 1; let-7, lethal-7; snoRNA, small nucleolar RNA; Nm, 2'-O-methylation; snRNA, small nuclear RNA; Snord32A, small nucleolar RNA C/D Box 32A; ADAR1, adenosine deaminase acting on RNA 1; CELF1, CUGBP Elav-like family member 1; OGG1, 8-oxoguanine glycosylase; OxoG, 8-oxoguanine. 
Table I. Epitranscriptomic modifications in CVDs.

A, Methylation

\begin{tabular}{|c|c|c|c|c|}
\hline Modification & Coding RNAs influenced & $\begin{array}{l}\text { Pathologies associated } \\
\text { with coding RNAs }\end{array}$ & $\begin{array}{l}\text { ncRNAs } \\
\text { influenced }\end{array}$ & $\begin{array}{l}\text { Pathologies associated } \\
\text { with ncRNAs }\end{array}$ \\
\hline $\mathrm{m}^{6} \mathrm{~A}$ & $\begin{array}{l}\text { 6PGD, MAP3K6, MAP4K5, } \\
\text { MAPK14, p53, TFEB, } \\
\text { CCNA2, CDK2, } \\
\text { PNPLA2, p65, p38, } \\
\text { SERCA2a, KLOTHO, } \\
\text { SIRT1, p16, } \\
\text { FBLN5, TNC }\end{array}$ & $\begin{array}{l}\text { Cardiac remodeling, } \\
\text { atherosclerosis, heart failure, } \\
\text { congenital heart disease, } \\
\text { CVD-related risk factors, } \\
\text { cardiac fibrosis, myocardial } \\
\text { infraction, myocardial ischemia, } \\
\text { stroke, aortic dissections, } \\
\text { cardiac hypertrophy, dilated } \\
\text { cardiomyopathy, diabetic } \\
\text { cardiomyopathy, chemotherapy } \\
\text { induced cardiotoxicity }\end{array}$ & $\begin{array}{l}\operatorname{miR}-126, \\
\operatorname{miR}-221 / 222, \\
\text { XIST }\end{array}$ & $\begin{array}{l}\text { H/R-induced injury, } \\
\text { atherosclerosis, } \\
\text { myocardial infraction }\end{array}$ \\
\hline $\mathrm{m}^{1} \mathrm{~A}$ & N/A & N/A & $\begin{array}{l}\text { mt-tRNAs, } \\
\text { rRNAs }\end{array}$ & $\begin{array}{l}\text { Coronary artery disease, } \\
\text { cardiac remodeling, } \\
\text { hypertrophic, } \\
\text { cardiomyopathy } \\
\text { dilated cardiomyopathy, } \\
\text { diabetic cardiomyopathy, } \\
\text { atherosclerosis, } \\
\text { chemotherapy-induced } \\
\text { cardiotoxicity }\end{array}$ \\
\hline $\mathrm{m}^{3} \mathrm{C}$ & DALRD3 & $\begin{array}{l}\text { Mild congenital heart disease, } \\
\text { developmental delay } \\
\text { and early-onset epileptic } \\
\text { encephalopathy }\end{array}$ & N/A & N/A \\
\hline $\mathrm{m}^{5} \mathrm{C}$ & $\begin{array}{l}\text { P-Tefb, ICAM-1, } \\
\text { IL-17A }\end{array}$ & $\begin{array}{l}\text { Cardiac hypertrophy, vascular } \\
\text { inflammation, atherosclerosis }\end{array}$ & $\begin{array}{l}\text { Rn7sk, } \\
\text { miR-125b }\end{array}$ & $\begin{array}{l}\text { Cardiac hypertrophy, } \\
\text { atherosclerosis }\end{array}$ \\
\hline $\mathrm{hm}^{5} \mathrm{C}$ & TET genes ${ }^{\mathrm{a}}$ & $\begin{array}{l}\text { Non-compaction } \\
\text { cardiomyopathy }\end{array}$ & N/A & N/A \\
\hline $\mathrm{m}^{7} \mathrm{G}$ & N/A & N/A & let-7 & $\begin{array}{l}\text { Myocardial infraction, } \\
\text { cardiac hypertrophy, } \\
\text { dilated } \\
\text { cardiomyopathy }\end{array}$ \\
\hline $\mathrm{Nm}$ & Peroxidasin & $\begin{array}{l}\text { Altered peroxidase activity } \\
\text { in the heart }\end{array}$ & N/A & N/A \\
\hline
\end{tabular}

B, Substitutions

\begin{tabular}{|c|c|c|c|c|}
\hline Modification & Coding RNAs influenced & $\begin{array}{l}\text { Pathologies associated } \\
\text { with coding RNAs }\end{array}$ & $\begin{array}{l}\text { ncRNAs } \\
\text { influenced }\end{array}$ & $\begin{array}{c}\text { Pathologies associated } \\
\text { with ncRNAs }\end{array}$ \\
\hline A-to-I & CTSS, FLNA & $\begin{array}{l}\text { Atherosclerosis, severe } \\
\text { ventricular remodeling, } \\
\text { cardiac remodeling, left } \\
\text { ventricular hypertrophy }\end{array}$ & $\begin{array}{l}\operatorname{miR}-199 a-5 p \\
\operatorname{miR}-478 b-3 p\end{array}$ & $\begin{array}{l}\text { Severe ventricular } \\
\text { remodeling, } \\
\text { ischemia response }\end{array}$ \\
\hline C-to-U & $\begin{array}{l}\text { CELF1, } \\
\text { APOBEC3A }\end{array}$ & $\begin{array}{l}\text { Neonatal cardiac } \\
\text { dysfunction, editing of } \\
\text { primary pulmonary } \\
\text { hypertension genes }\end{array}$ & & \\
\hline
\end{tabular}


Table I. Continued.

\section{C, Other}

\begin{tabular}{lllll}
\hline Modification & $\begin{array}{c}\text { Coding RNAs } \\
\text { influenced }\end{array}$ & $\begin{array}{c}\text { Pathologies associated } \\
\text { with coding RNAs }\end{array}$ & $\begin{array}{c}\text { ncRNAs } \\
\text { influenced }\end{array}$ & $\begin{array}{c}\text { Pathologies associated } \\
\text { with ncRNAs }\end{array}$ \\
\hline$\Psi$ & N/A & N/A & KCNQ1OT1 & Myocardial infraction \\
8-OxoG & Differences in & CVD-related risk & miR-1 & Cardiac hypertrophy \\
& OGG1 levels & factors, cardiac & & \\
& fibrosis, blood & & \\
& pressure levels & & \\
& & & & \\
\end{tabular}

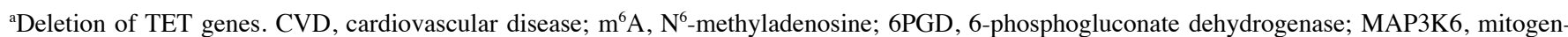
activated protein kinase kinase kinase 6; MAP4K5, mitogen-activated protein kinase kinase kinase kinase 5; MAPK14, mitogen-activated protein kinase 14; TFEB, transcription factor EB; CCNA2, cyclin A2; PNPLA2, patatin-like phospholipase domain containing 2; SERCA2a, sarco/endoplasmic reticulum $\mathrm{Ca}^{2+}$-ATPase 2a; FBLN5, fibulin; 5KLOTHO, klotho $\beta$-glucuronidase; TNC, tenascin C; H/R, hypoxia/reoxygenation; miR, microRNA; ncRNA, non-coding RNA; XIST, X-inactive specific transcript; $\mathrm{m}^{1} \mathrm{~A}, \mathrm{~N}^{1}$-methyladenosine; tRNA, transfer RNA; rRNA, ribosomal RNA; ${ }^{3} \mathrm{C}, 3$-methylcytosine; $\mathrm{m}^{5} \mathrm{C}$, 5-methylcytosine; $\mathrm{hm}^{5} \mathrm{C}, 5$-hydroxymethylcytosine; $\mathrm{m}^{7} \mathrm{G}, 7$-methylguanosine; $\mathrm{Nm}, 2^{2}$-O-methylation; DALRD3, DALR anticodon binding domain containing 3; P-Tefb, positive transcription elongation factor b; ICAM-1, intercellular adhesion molecule 1; Rn7sk, RNA component of 7SK nuclear ribonucleoprotein; TET, methylcytosine dioxygenase; let-7, lethal-7; CTSS, cathepsin S; FLNA, Filamin A; CELF1, CUGBP Elav-like family member 1; APOBEC3A, apolipoprotein B mRNA editing enzyme catalytic polypeptide-like 3A; $\Psi$, pseudouridylation; KCNQ1OT1, KCNQ1 opposite strand/antisense transcript 1; OGG1, 8-oxoguanine glycosylase; OxoG, 8-oxoguanine.

in this case, involved miR-199a-5p, exhibiting the intricate and dynamic regulation that such modifications offer in tandem with ncRNA regulation. This fact is further highlighted by studies by van der Kwast et al $(44,260)$, where A-to-I editing of miR-478b-3p created an isomiR with a completely different targetome and extensive angiogenic pathway effects, further establishing the relationship between epitranscriptomic modification and miRNA-mediated regulation. Alongside A-to-U editing events, C-to-U editing offers a much more delicate regulation network, with increased specificity. Although cardiac-specific effects in vivo have yet to be reported in relation to $\mathrm{C}$-to-U editing, the expression of the tissue-specific APOBEC-2 deaminase in the heart, coupled with the capacity of APOBEC3A to edit hypertension genes under hypoxic conditions in vitro, point to still unexplored events, similar to the editing of apolipoprotein in the liver, in a tissue-specific manner.

In this context, cardiac aging has recently emerged as an exciting new field, exploring among others, the possible connection between RNA modifications and the various morphological and biomolecular changes that take place during the cardiac aging process. Increased cardiac fibrosis, left ventricular hypertrophy and valvular degeneration are just some of the main physiological changes that occur during human cardiac aging (261). Of note, cardiac fibrosis emergence has been linked to changes in RNA modifications, such as $\mathrm{m}^{6} \mathrm{~A}$ and inosine (262), while cardiomyocyte aging has been found to be affected by RNA methylation (263). Cardiomyocyte hypertrophy, responsible for the thickening of the left ventricle walls during cardiac aging, has also been linked to $\mathrm{m}^{6} \mathrm{~A}$ methylation. More specifically, in vitro and in vivo experiments have shown that $\mathrm{m}^{6} \mathrm{~A}$ RNA methylase METTL3 could promote cardiomyocyte hypertrophy, whereas METTL3 inhibition inhibited the hypertrophic potential of cardiomyocytes (78). All of the above provide just a glimpse of the still unexplored effects that epitranscriptomic regulation may potentially have during cardiac aging.
Finally, a large number of modifications have also been detected in mitochondria. Due to the importance of mitochondria for physiological cardiac function, these editing events can have severe implications for both homeostasis and disease emergence. HF, despite its various complications, has historically been studied as a left ventricular disease. As such, $\mathrm{m}^{1} \mathrm{~A}$ modifications in mitochondrial 16s rRNA, as well as tRNAs, but also components of the mitochondrial complex I (such as mt-ND5) in the left ventricle, can have severe implications for both $\mathrm{HF}$ and various other CVDs. Additionally, NSUN4-mediated mitochondrial $\mathrm{m}^{5} \mathrm{C}$ methylation is required for physiological function, as shown by the emergence of cardiomyopathy, after NSUN4 cardiac-specific deletion. While examining mitochondrial RNA methylation, Van Haute et al (264) demonstrated NSUN3 as a novel human $\mathrm{m}^{5} \mathrm{C}$ RNA methyltransferase, specializing in mitochondrial tRNA $^{\text {Met }}$. Mutations of NSUN3 caused reduced methylation and absence of formulation of cytosine residues at position 34 of the mitochondrial tRNA ${ }^{\mathrm{Met}}$, leading to reduced mitochondrial translation and the development of mitochondrial disease. Thus, mitochondrial RNA methylation seems to affect mitochondrial function as well as the translation of mitochondrial proteins, leading to the emergence of pathology (264). Even though other mitochondrial RNA modifications have not been implicated in CVD, it is safe to assume that we are only starting to scratch the surface, as various more mitochondrial modifications have been described, such as $\Psi$ modifications. As already reviewed by Bohnsack and Sloan (265), the mitochondrial epitranscriptome is rapidly gaining interest as a key regulator of dynamic, efficient and accurate responses to metabolic needs. Mutations in mitochondrial RNase $\mathrm{P}$ protein 2, a mitochondrial RNase $\mathrm{P}$ subcomplex cofactor, participating in $\mathrm{m}^{1} \mathrm{~A}$ and $\mathrm{m} 1 \mathrm{G}$ mt-tRNA modifications, were shown to cause cardiomyopathy $(106,266)$. Last, but not least, a few RNA modifications, such as C-to- $\mathrm{U}$ editing by APOBEC $3 \mathrm{~A}$ or $\mathrm{m}^{6} \mathrm{~A}$ modification of the FTO protein were shown to be manifesting 
during hypoxic conditions. Taking into account the extensive role of hypoxia in metabolic regulation, mitochondrial biogenesis and cardiac remodeling, such modifications further cement the role of epitranscriptomic regulation in the adaptation to ever-changing environmental stimuli both in physiological, but also in pathological conditions.

This new knowledge is now paving the way towards a new chapter in personalized medicine (267), where an in-depth understanding of epitranscriptomic modifications could not only enable more accurate patient classification based on epitranscriptomic 'profiles' or specific epitranscriptomic biomarkers, but, more importantly, allow for early predictions of response to treatment. Early evidence in this direction stems from the area of oncology, where specific RNA modifications (e.g. ${ }^{6} \mathrm{~A}$ ) appear to be associated with therapeutic response and/or resistance (268). Significant promise also lies in the development of novel targeted epitranscriptomic therapies against CVD. The fine mapping of the role of epitranscriptomic changes in different aspects of CVD development, is likely to unveil a multitude of promising therapeutic targets, that could subsequently be modulated by targeted approaches, such as small molecule inhibitors. A number of such approaches are currently being pursued against FTO in the milieu of cancer (269). For example, the US Food and Drug Administration-approved nonsteroidal anti-inflammatory drug ethyl ester form of MA, MA2, was found to be an FTO inhibitor, which led to elevated levels of $\mathrm{m}^{6} \mathrm{~A}$ modification in mRNAs in glioblastoma cells, suppressing tumor progression and prolonging the lifespan of glioblastoma stem cell-grafted mice (270). MO-I-500 was developed to selectively inhibit the $\mathrm{m}^{6} \mathrm{~A}$ demethylase activity of FTO and was found to successfully inhibit the survival and/or colony formation of a triple-negative inflammatory breast cancer cells $(271,272)$. R-2HG was found to bind directly to FTO and inhibit $\mathrm{m}^{6} \mathrm{~A}$ demethylase activity leading to the inhibition of leukemic cell growth/survival and leukemia progression (273). FB23-2 was also effective in inhibiting the progression of human AML in xenotransplantation mice, by achieving the potent inhibition of FTO (274). In an effort to expedite the discovery of such inhibitors different predictive in silico approaches are also employed (275-279). The majority of the aforementioned approaches are based on conventional pipelines on databases' data management $(280,281)$. However, at present in the post-genomic era, state-of-the-art approaches based on artificial intelligence are being employed, thus providing novel and radical solutions for the management and analysis of high amounts of data, where algorithms and convolutional networks not only decipher information by removing noise and reducing dimensionality, but also produce new knowledge and associations (282). The tremendous clinical potential of these advancements is supported by the early establishment of multiple companies focusing on epitranscriptomics, such as Accent, Gotham and Storm Therapeutics. It is only a matter of time before similar avenues are explored in the field of CVD, as evidenced by recent studies on epitranscriptomic modification-based therapy solutions.

All of the above serve to show we currently stand at the shore of cardiac epitranscriptomic research, where a vast ocean of information still remains unexplored. We still have to understand the relationship between the number of modifications that each coding or ncRNA carries, to their respective effect, or the methods of action for tissue-specific RNA modifications in response to physiological or pathological stimuli. As we delve deeper into CVD epitranscriptomics, we are sure to come closer to the 'holy grail' of personalized medicine and targeted therapeutics.

\section{Acknowledgements}

Not applicable.

\section{Funding}

The authors would like to acknowledge funding from the following organizations: i) CURE-PLaN grant from the Leducq Foundation for Cardiovascular Research (grant no. 18CVD01); ii) AdjustEBOVGP-Dx (grant no. RIA2018EF-2081): Biochemical Adjustments of native EBOV Glycoprotein in Patient Sample to Unmask target Epitopes for Rapid Diagnostic Testing. A European and Developing Countries Clinical Trials Partnership (EDCTP2) under the Horizon 2020 'Research and Innovation Actions' DESCA; and iii) 'MilkSafe: A novel pipeline to enrich formula milk using omics technologies', a research co-financed by the European Regional Development Fund of the European Union and Greek national funds through the Operational Program Competitiveness, Entrepreneurship and Innovation, under the call RESEARCH-CREATE-INNOVATE (project no. T2EDK-02222).

\section{Availability of data and materials}

Not applicable.

\section{Authors' contributions}

SL, EP, KID, KP, TM, KD, FB, DS, GPC and DV contributed to conceptualization, designing, writing, drafting, revising, editing and reviewing of the manuscript. Data authentication is not applicable. All authors have read and approved the final manuscript.

\section{Ethics approval and consent to participate}

Not applicable.

\section{Patient consent for publication}

Not applicable.

\section{Competing interests}

The authors declare that they have no competing interests.

\section{References}

1. Manzoni C, Kia DA, Vandrovcova J, Hardy J, Wood NW Lewis PA and Ferrari R: Genome, transcriptome and proteome: The rise of omics data and their integration in biomedical sciences. Brief Bioinform 19: 286-302, 2018

2. Buriani A, Fortinguerra S, Sorrenti V, Gabbia D and Carrara M: Single-cell omics in personalized medicine. In: Single-Cell Omics. Barh D and Azevedo V (eds). Academic Press, Cambridge, MA, pp221-236, 2019. 
3. Korenke GC, Fuchs S, Krasemann E, Doerr HG, Wilichowski E, Hunneman DH and Hanefeld F: Cerebral adrenoleukodystrophy (ALD) in only one of monozygotic twins with an identical ALD genotype. Ann Neurol 40: 254-257, 1996.

4. Cavalli G and Heard E: Advances in epigenetics link genetics to the environment and disease. Nature 571: 489-499, 2019.

5. Sarkies P: Molecular mechanisms of epigenetic inheritance: Possible evolutionary implications. Semin Cell Dev Biol 97: $106-115,2020$

6. Qureshi IA and Mehler MF: Epigenetic mechanisms underlying nervous system diseases. Handb Clin Neurol 147: 43-58, 2018.

7. Schwartz S: Cracking the epitranscriptome. RNA 22: 169-174, 2016.

8. Boccaletto P, Machnicka MA, Purta E, Piatkowski P, Baginski B, Wirecki TK, de Crécy-Lagard V, Ross R, Limbach PA, Kotter A, et al: MODOMICS: A database of RNA modification pathways. 2017 update. Nucleic Acids Res 46: D303-D307, 2018

9. Czerwoniec A, Dunin-Horkawicz S, Purta E, Kaminska KH, Kasprzak JM, Bujnicki JM, Grosjean $\mathrm{H}$ and Rother K MODOMICS: A database of RNA modification pathways. 2008 update. Nucleic Acids Res 37: D118-D121, 2009.

10. Dunin-Horkawicz S, Czerwoniec A, Gajda MJ, Feder M, Grosjean $\mathrm{H}$ and Bujnicki JM: MODOMICS: A database of RNA modification pathways. Nucleic Acids Res 34: D145-D149, 2006.

11. Machnicka MA, Milanowska K, Osman Oglou O, Purta E, Kurkowska M, Olchowik A, Januszewski W, Kalinowski S, Dunin-Horkawicz S, Rother KM, et al: MODOMICS: A database of RNA modification pathways--2013 update. Nucleic Acids Res 41: D262-D267, 2013

12. Xuan JJ, Sun WJ, Lin PH, Zhou KR, Liu S, Zheng LL, Qu LH and Yang JH: RMBase v2.0: Deciphering the map of RNA modifications from epitranscriptome sequencing data. Nucleic Acids Res 46: D327-D334, 2018.

13. Kiran AM, O'Mahony JJ, Sanjeev K and Baranov PV: Darned in 2013: Inclusion of model organisms and linking with Wikipedia. Nucleic Acids Res 41: D258-D261, 2013.

14. Cantara WA, Crain PF, Rozenski J, McCloskey JA, Harris KA, Zhang X, Vendeix FA, Fabris D and Agris PF: The RNA Modification Database, RNAMDB: 2011 update. Nucleic Acids Res 39: D195-D201, 2011.

15. Picardi E, D'Erchia AM,Lo Giudice C and Pesole G: REDIportal: A comprehensive database of A-to-I RNA editing events in humans. Nucleic Acids Res 45: D750-D757, 2017.

16. Schuebel K, Gitik M, Domschke K and Goldman D: Making sense of epigenetics. Int J Neuropsychopharmacol 19: pyw058, 2016.

17. Kumari R, Ranjan P, Suleiman ZG, Goswami SK, Li J, Prasad R and Verma SK: mRNA modifications in cardiovascular biology and disease: With a focus on m6A modification. Cardiovasc Res: May 6, 2021 (Epub ahead of print). doi: 10.1093/cvr/cvab160

18. Chen YS, Ouyang XP, Yu XH, Novák P, Zhou L, He P and Yin K: N6-adenosine methylation (m(6)A) RNA modification: An emerging role in cardiovascular diseases. J Cardiovasc Transl Res: Feb 25, 2021 (Epub ahead of print). doi: 10.1007/s12265021-10108-w.

19. Napoli C, Benincasa G, Donatelli F and Ambrosio G: Precision medicine in distinct heart failure phenotypes: Focus on clinical epigenetics. Am Heart J 224: 113-128, 2020.

20. Fischer MA and Vondriska TM: Clinical epigenomics for cardiovascular disease: Diagnostics and therapies. J Mol Cell Cardiol 154: 97-105, 2021.

21. Schiano C, Benincasa G, Franzese M, Della Mura N, Pane K Salvatore $M$ and Napoli C: Epigenetic-sensitive pathways in personalized therapy of major cardiovascular diseases. Pharmacol Ther 210: 107514, 2020.

22. Vlachakis C, Dragoumani K, Raftopoulou S, Mantaiou M Papageorgiou L, Champeris Tsaniras S, Megalooikonomou V and Vlachakis D: Human emotions on the onset of cardiovascular and small vessel related diseases. In Vivo 32: 859-870, 2018

23. Timmis A, Townsend N, Gale CP, Torbica A, Lettino M, Petersen SE, Mossialos EA, Maggioni AP, Kazakiewicz D, May HT, et al; European Society of Cardiology: European Society of Cardiology: Cardiovascular Disease Statistics 2019. Eur Heart J 41: 12-85, 2020.

24. Flora GD and Nayak MK: A brief review of cardiovascular diseases, associated risk factors and current treatment regimes. Curr Pharm Des 25: 4063-4084, 2019.

25. Baccarelli A, Rienstra M and Benjamin EJ: Cardiovascular epigenetics: Basic concepts and results from animal and human studies. Circ Cardiovasc Genet 3: 567-573, 2010.
26. Zhong J, Agha G and Baccarelli AA: The role of DNA methylation in cardiovascular risk and disease: Methodological aspects, study design, and data analysis for epidemiological studies. Circ Res 118 119-131, 2016.

27. Vlachakis D, Zacharaki EI, Tsiamaki E, Koulouri M, Raftopoulou S, Papageorgiou L, Chrousos GP, Ellul J and Megalooikonomou V: Insights into the molecular mechanisms of stress and inflammation in ageing and frailty of the elderly. J Mol Biochem 6: 41-44, 2017.

28. Guerra J, Valadao AL, Vlachakis D, Polak K, Vila IK, Taffoni C, Prabakaran T, Marriott AS, Kaczmarek R, Houel A, et al: Lysyl-tRNA synthetase produces diadenosine tetraphosphate to curb STING-dependent inflammation. Sci Adv 6: eaax3333, 2020.

29. Soler-Botija C, Gálvez-Montón C and Bayés-Genís A: Epigenetic biomarkers in cardiovascular diseases. Front Genet 10: 950-950, 2019.

30. Shi H, Wei J and He C: Where, when, and how: Context-dependent functions of RNA methylation writers, readers, and erasers. Mol Cell 74: 640-650, 2019.

31. Zaccara S, Ries RJ and Jaffrey SR: Reading, writing and erasing mRNA methylation. Nat Rev Mol Cell Biol 20: 608-624, 2019.

32. Gatsiou A and Stellos K: Dawn of epitranscriptomic medicine. Circ Genom Precis Med 11: e001927, 2018.

33. Anreiter I, Mir Q, Simpson JT, Janga SC and Soller M: New twists in detecting mRNA modification dynamics. Trends Biotechnol 39: 72-89, 2021.

34. Mongelli A, Atlante S, Bachetti T, Martelli F, Farsetti A and Gaetano C: Epigenetic signaling and RNA regulation in cardiovascular diseases. Int J Mol Sci 21: 509, 2020.

35. Zhang P, Wu W, Chen Q and Chen M: Non-coding RNAs and their integrated networks. J Integr Bioinform 16: 16, 2019.

36. Gomes CPC, Schroen B, Kuster GM, Robinson EL, Ford K, Squire IB, Heymans S, Martelli F, Emanueli C and Devaux Y; EU-CardioRNA COST action (CA17129): Regulatory RNAs in heart failure. Circulation 141: 313-328, 2020.

37. Esteller M and Pandolfi PP: The epitranscriptome of noncoding RNAs in cancer. Cancer Discov 7: 359-368, 2017.

38. Blow MJ, Grocock RJ, van Dongen S, Enright AJ, Dicks E, Futreal PA, Wooster R and Stratton MR: RNA editing of human microRNAs. Genome Biol 7: R27, 2006.

39. Zhang Y, Zang Q, Xu B, Zheng W, Ban R, Zhang H, Yang Y, Hao Q, Iqbal F, Li A, et al: IsomiR Bank: A research resource for tracking IsomiRs. Bioinformatics 32: 2069-2071, 2016.

40. Neilsen CT, Goodall GJ and Bracken CP: IsomiRs - the overlooked repertoire in the dynamic microRNAome. Trends Genet 28: 544-549, 2012.

41. Newman MA, Mani V and Hammond SM: Deep sequencing of microRNA precursors reveals extensive 3' end modification. RNA 17: 1795-1803, 2011

42. Cloonan N, Wani S, Xu Q, Gu J, Lea K, Heater S, Barbacioru C, Steptoe AL, Martin HC, Nourbakhsh E, et al: MicroRNAs and their isomiRs function cooperatively to target common biological pathways. Genome Biol 12: R126, 2011.

43. Manzano M, Forte E, Raja AN, Schipma MJ and Gottwein E: Divergent target recognition by coexpressed 5'-isomiRs of miR-142-3p and selective viral mimicry. RNA 21: 1606-1620, 2015.

44. van der Kwast RV, van Ingen E, Parma L, Peters HA, Quax PH and Nossent AY: Adenosine-to-inosine editing of MicroRNA-487b alters target gene selection after ischemia and promotes Neovascularization. Circ Res 122: 444-456, 2018.

45. van der Kwast RV, Woudenberg T, Quax PHA and Nossent AY: MicroRNA-411 and its 5'-IsomiR have distinct targets and functions and are differentially regulated in the vasculature under ischemia. Mol Ther 28: 157-170, 2020.

46. Gilbert WV, Bell TA and Schaening C: Messenger RNA modifications: Form, distribution, and function. Science 352: 1408-1412, 2016.

47. Yin L, Zhu X, Novák P, Zhou L, Gao L, Yang M, Zhao G and Yin K: The epitranscriptome of long noncoding RNAs in metabolic diseases. Clin Chim Acta 515: 80-89, 2021.

48. Zhou Y, Kong Y, Fan W, Tao T, Xiao Q, Li N and Zhu X: Principles of RNA methylation and their implications for biology and medicine. Biomed Pharmacother 131: 110731, 2020

49. Wulff BE and Nishikura K: Substitutional A-to-I RNA editing. Wiley Interdiscip Rev RNA 1: 90-101, 2010.

50. Blanc V and Davidson NO: C-to-U RNA editing: Mechanisms leading to genetic diversity. J Biol Chem 278: 1395-1398, 2003. 
51. Adachi H, De Zoysa MD and Yu YT: Post-transcriptional pseudouridylation in mRNA as well as in some major types of noncoding RNAs. Biochim Biophys Acta Gene Regul Mech 1862: 230-239, 2019.

52. Martinet W, De Meyer GR, Herman AG and Kockx MM: RNA damage in human atherosclerosis: Pathophysiological significance and implications for gene expression studies. RNA Biol 2: 4-7, 2005.

53. Desrosiers R, Friderici K and Rottman F: Identification of methylated nucleosides in messenger RNA from Novikoff hepatoma cells. Proc Natl Acad Sci USA 71: 3971-3975, 1974.

54. Perry RPK and Kelley DE: Existence of methylated messenger RNA in mouse L cells. Cell 1: 37-42, 1974.

55. Dominissini D, Moshitch-Moshkovitz S, Schwartz S, Salmon-Divon M, Ungar L, Osenberg S, Cesarkas K, Jacob-Hirsch J, Amariglio N, Kupiec M, et al: Topology of the human and mouse m6A RNA methylomes revealed by m6A-seq. Nature 485: 201-206, 2012.

56. Molinie B, Wang J, Lim KS, Hillebrand R, Lu ZX, Van Wittenberghe N, Howard BD, Daneshvar K, Mullen AC, Dedon P, et al: m(6)A-LAIC-seq reveals the census and complexity of the m(6)A epitranscriptome. Nat Methods 13: 692-698, 2016

57. Sun H, Li K, Zhang X, Liu J, Zhang M, Meng H and Yi C: m6Am-seq reveals the dynamic m6Am methylation in the human transcriptome. Nat Commun 12: 4778, 2021.

58. Meyer KD, Saletore Y, Zumbo P, Elemento O, Mason CE and Jaffrey SR: Comprehensive analysis of mRNA methylation reveals enrichment in 3' UTRs and near stop codons. Cell 149: 1635-1646, 2012.

59. Wang X, Lu Z, Gomez A, Hon GC, Yue Y, Han D, Fu Y, Parisien M, Dai Q, Jia G, et al: N6-methyladenosine-dependent regulation of messenger RNA stability. Nature 505: 117-120, 2014.

60. Meyer KD, Patil DP, Zhou J, Zinoviev A, Skabkin MA, Elemento O, Pestova TV, Qian SB and Jaffrey SR: 5' UTR m(6)a promotes cap-independent translation. Cell 163: 999-1010, 2015.

61. Wang X, Zhao BS, Roundtree IA, Lu Z, Han D, Ma H, Weng X, Chen K, Shi $\mathrm{H}$ and $\mathrm{He} \mathrm{C}$ : N(6)-methyladenosine Modulates Messenger RNA Translation Efficiency. Cell 161: 1388-1399, 2015.

62. Kierzek E and Kierzek R: The thermodynamic stability of RNA duplexes and hairpins containing N6-alkyladenosines and 2-methylthio-N6-alkyladenosines. Nucleic Acids Res 31: 4472-4480, 2003.

63. Liu N, Dai Q, Zheng G, He C, Parisien M and Pan T: $\mathrm{N}(6)$-methyladenosine-dependent RNA structural switches regulate RNA-protein interactions. Nature 518: 560-564, 2015.

64. Xiao W, Adhikari S, Dahal U, Chen YS, Hao YJ, Sun BF, Sun HY, Li A, Ping XL, Lai WY, et al: Nuclear m(6)A reader YTHDC1 regulates mRNA splicing. Mol Cell 61: 507-519, 2016.

65. Balatsos NA, Vlachakis D, Maragozidis P, Manta S, Anastasakis D, Kyritsis A, Vlassi M,Komiotis D and Stathopoulos C: Competitive inhibition of human poly(A)-specific ribonuclease (PARN) by synthetic fluoro-pyranosyl nucleosides. Biochemistry 48 : 6044-6051, 2009.

66. Balatsos N, Vlachakis D, Chatzigeorgiou V, Manta S, Komiotis D, Vlassi M and Stathopoulos C: Kinetic and in silico analysis of the slow-binding inhibition of human poly(A)-specific ribonuclease (PARN) by novel nucleoside analogues. Biochimie 94: 214-221, 2012.

67. Fustin JM, Doi M, Yamaguchi Y, Hida H, Nishimura S, Yoshida M, Isagawa T, Morioka MS, Kakeya H, Manabe I, et al: RNA-methylation-dependent RNA processing controls the speed of the circadian clock. Cell 155: 793-806, 2013

68. Xiang Y, Laurent B, Hsu CH, Nachtergaele S, Lu Z, Sheng W, $\mathrm{Xu} \mathrm{C}$, Chen $\mathrm{H}$, Ouyang J, Wang $\mathrm{S}$, et al: RNA m6A methylation regulates the ultraviolet-induced DNA damage response. Nature 543: 573-576, 2017.

69. Liu J, Yue Y, Han D, Wang X, Fu Y, Zhang L, Jia G, Yu M, Lu Z, Deng X, et al: A METTL3-METTL14 complex mediates mammalian nuclear RNA N6-adenosine methylation. Nat Chem Biol 10: 93-95, 2014.

70. Wang Y, Li Y, Toth JI, Petroski MD, Zhang Z and Zhao JC: N6-methyladenosine modification destabilizes developmental regulators in embryonic stem cells. Nat Cell Biol 16: 191-198, 2014.

71. Ping XL, Sun BF, Wang L, Xiao W, Yang X, Wang WJ, Adhikari S, Shi Y, Lv Y, Chen YS, et al: Mammalian WTAP is a regulatory subunit of the RNA N6-methyladenosine methyltransferase. Cell Res 24: 177-189, 2014
72. Schwartz S, Mumbach MR, Jovanovic M, Wang T, Maciag K, Bushkin GG, Mertins P, Ter-Ovanesyan D, Habib N, Cacchiarelli D, et al: Perturbation of m6A writers reveals two distinct classes of mRNA methylation at internal and 5' sites. Cell Rep 8: 284-296, 2014

73. Wang X, Feng J, Xue Y, Guan Z, Zhang D, Liu Z, Gong Z, Wang Q, Huang J, Tang C, et al: Structural basis of N(6)-adenosine methylation by the METTL3-METTL14 complex. Nature 534: 575-578, 2016.

74. Meyer KD and Jaffrey SR: Rethinking m6A readers, writers, and erasers. Annu Rev Cell Dev Biol 33: 319-342, 2017.

75. Longenecker JZ, Gilbert CJ, Golubeva VA, Martens CR and Accornero F: Epitranscriptomics in the heart: A focus on m6A. Curr Heart Fail Rep 17: 205-212, 2020.

76. Qin Y, Li L, Luo E, Hou J, Yan G, Wang D, Qiao Y and Tang C: Role of m6A RNA methylation in cardiovascular disease (Review). Int J Mol Med 46: 1958-1972, 2020.

77. Zheng N, Su J, Hu H, Wang J and Chen X: Research progress of N6-methyladenosine in the cardiovascular system. Med Sci Monit 26: e921742, 2020.

78. Dorn LE, Lasman L, Chen J, Xu X, Hund TJ, Medvedovic M, HannaJH,vanBerloJHand AccorneroF:The N6-methyladenosine mRNA methylase METTL3 controls cardiac homeostasis and hypertrophy. Circulation 139: 533-545, 2019.

79. Song H, Pu J, Wang L, Wu L, Xiao J, Liu Q, Chen J, Zhang M, Liu Y, Ni M, et al: ATG16L1 phosphorylation is oppositely regulated by CSNK2/casein kinase 2 and PPP1/protein phosphatase 1 which determines the fate of cardiomyocytes during hypoxia/reoxygenation. Autophagy 11: 1308-1325, 2015

80. Pastore N, Brady OA, Diab HI, Martina JA, Sun L, Huynh T, Lim JA, Zare H, Raben N, Ballabio A, et al: TFEB and TFE3 cooperate in the regulation of the innate immune response in activated macrophages. Autophagy 12: 1240-1258, 2016.

81. Zhao E and Czaja MJ: Transcription factor EB: A central regulator of both the autophagosome and lysosome. Hepatology 55: 1632-1634, 2012

82. Song H, Feng X, Zhang H, Luo Y, Huang J, Lin M, Jin J, Ding X, Wu S, Huang H, et al: METTL3 and ALKBH5 oppositely regulate m6A modification of TFEB mRNA, which dictates the fate of hypoxia/reoxygenation-treated cardiomyocytes. Autophagy 15: 1419-1437, 2019

83. Kmietczyk V, Riechert E, Kalinski L, Boileau E, Malovrh E, Malone B, Gorska A, Hofmann C, Varma E, Jürgensen L, et al: m6A-mRNA methylation regulates cardiac gene expression and cellular growth. Life Sci Alliance 2: e201800233, 2019.

84. Berulava T, BuchholzE, Elerdashvili V,Pena T, Islam MR,Lbik D, Mohamed BA, Renner A, von Lewinski D, Sacherer M, et al: Changes in m6A RNA methylation contribute to heart failure progression by modulating translation. Eur J Heart Fail 22: 54-66, 2020.

85. Fischer J, Koch L, Emmerling C, Vierkotten J, Peters T, Brüning JC and Rüther U: Inactivation of the Fto gene protects from obesity. Nature 458: 894-898, 2009.

86. Mathiyalagan P, Adamiak M, Mayourian J, Sassi Y, Liang Y, Agarwal N, Jha D, Zhang S, Kohlbrenner E, Chepurko E, et al: FTO-dependent N6-methyladenosine regulates cardiac function during remodeling and repair. Circulation 139: 518-532, 2019.

87. Mathiyalagan P, Adamiak M, Mayourian J, Sassi Y, Liang Y, Agarwal N, Jha D, Shihong Zhang S, Kohlbrenner E, Chepurko E, et al: FTO-dependent m6A regulates cardiac function during remodeling and repair. Circulation 139: 518-532, 2019.

88. Michlewski G and Cáceres JF: Post-transcriptional control of miRNA biogenesis. RNA 25: 1-16, 2019.

89. Ma JZ, Yang F, Zhou CC, Liu F, Yuan JH, Wang F, Wang TT, $\mathrm{Xu}$ QG, Zhou WP and Sun SH: METTL14 suppresses the metastatic potential of hepatocellular carcinoma by modulating N6-methyladenosine-dependent primary MicroRNA processing. Hepatology 65: 529-543, 2017.

90. Han J, Wang JZ, Yang X, Yu H, Zhou R, Lu HC, Yuan WB, Lu JC, Zhou ZJ, Lu Q, et al: METTL3 promote tumor proliferation of bladder cancer by accelerating pri-miR221/222 maturation in m6A-dependent manner. Mol Cancer 18: 110, 2019.

91. Baarsma H and Königshoff M: 'WNT-er is coming': WNT signalling in chronic lung diseases. Thorax 72: 746-759, 2017.

92. Savai R, Al-Tamari HM, Sedding D, Kojonazarov B, Muecke C, Teske R, Capecchi MR, Weissmann N, Grimminger F, Seeger W, et al: Pro-proliferative and inflammatory signaling converge on FoxO1 transcription factor in pulmonary hypertension. Nat Med 20: 1289-1300, 2014 
93.Lin B, Xu J, Wang F, Wang J, Zhao H and Feng D: LncRNA XIST promotes myocardial infarction by regulating FOS through targeting miR-101a-3p. Aging (Albany NY) 12: 7232-7247, 2020.

94.Patil DP, Chen CK, Pickering BF, Chow A, Jackson C, Guttman M and Jaffrey SR: m(6)A RNA methylation promotes XIST-mediated transcriptional repression. Nature 537: 369-373, 2016

95. Sun R and Zhang L: Long non-coding RNA MALAT1 regulates cardiomyocytes apoptosis after hypoxia/reperfusion injury via modulating miR-200a-3p/PDCD4 axis. Biomed Pharmacother 111: 1036-1045, 2019.

96.Liu N, Parisien M, Dai Q, Zheng G, He C and Pan T: Probing N6-methyladenosine RNA modification status at single nucleotide resolution in mRNA and long noncoding RNA. RNA 19: 1848-1856, 2013.

97. Spitale RC, Flynn RA, Zhang QC, Crisalli P, Lee B, Jung JW, Kuchelmeister HY, Batista PJ, Torre EA, Kool ET, et al Erratum: Structural imprints in vivo decode RNA regulatory mechanisms. Nature 527: 264, 2015.

98. Coker H, Wei $\mathrm{G}$ and Brockdorff $\mathrm{N}$ : m6A modification of non-coding RNA and the control of mammalian gene expression. Biochim Biophys Acta Gene Regul Mech 1862: 310-318, 2019.

99. Mendel M, Chen KM, Homolka D, Gos P, Pandey RR, McCarthy AA and Pillai RS: Methylation of structured RNA by the m6A writer METTL16 is essential for mouse embryonic development. Mol Cell 71: 986-1000.e11, 2018.

100. Brown JA, Kinzig CG, DeGregorio SJ and Steitz JA: Methyltransferase-like protein 16 binds the 3'-terminal triple helix of MALAT1 long noncoding RNA. Proc Natl Acad Sci USA 113: 14013-14018, 2016.

101.Dunn DB: The occurrence of 1-methyladenine in ribonucleic acid. Biochim Biophys Acta 46: 198-200, 1961.

102. Agris PF: The importance of being modified: Roles of modified nucleosides and $\mathrm{Mg}^{2+}$ in RNA structure and function. Prog Nucleic Acid Res Mol Biol 53: 79-129, 1996.

103.Xiong X, Li X and Yi C: N1-methyladenosine methylome in messenger RNA and non-coding RNA. Curr Opin Chem Biol 45: 179-186, 2018

104. Waku T, Nakajima Y, Yokoyama W, Nomura N, Kako K Kobayashi A, Shimizu T and Fukamizu A: NML-mediated rRNA base methylation links ribosomal subunit formation to cell proliferation in a p53-dependent manner. J Cell Sci 129 2382-2393, 2016.

105. Chujo T and Suzuki T: Trmt61B is a methyltransferase responsible for 1-methyladenosine at position 58 of human mitochondrial tRNAs. RNA 18: 2269-2276, 2012.

106. Vilardo E, Nachbagauer C, Buzet A, Taschner A, Holzmann J and Rossmanith W: A subcomplex of human mitochondrial RNase $\mathrm{P}$ is a bifunctional methyltransferase - extensive moonlighting in mitochondrial tRNA biogenesis. Nucleic Acids Res 40: 11583-11593, 2012.

107. Ozanick S, Krecic A, Andersland J and Anderson JT: The bipartite structure of the tRNA m1A58 methyltransferase from S. cerevisiae is conserved in humans. RNA 11: 1281-1290, 2005.

108.Zhang C and Jia G: Reversible RNA modification N1methyladenosine (m1A) in mRNA and tRNA. Genomics Proteomics Bioinformatics 16: 155-161, 2018.

109. Shi Q, Xue C, Yuan X, He Y and Yu Z: Gene signatures and prognostic values of m1A-related regulatory genes in hepatocellular carcinoma. Sci Rep 10: 15083, 2020.

110.Li X, Xiong X, Zhang M, Wang K, Chen Y, Zhou J, Mao Y, Lv J, Yi D, Chen XW, et al: Base-resolution mapping reveals distinct m1 A methylome in nuclear- and mitochondrial-encoded transcripts. Mol Cell 68: 993-1005.e9, 2017.

111. Siasos G, Tsigkou V, Kosmopoulos M, Theodosiadis D, Simantiris S, Tagkou NM, Tsimpiktsioglou A,StampouloglouPK, Oikonomou E, Mourouzis K, et al: Mitochondria and cardiovascular diseases-from pathophysiology to treatment. Ann Transl Med 6: 256, 2018

112. Poznyak AV, Ivanova EA, Sobenin IA, Yet SF and Orekhov AN: The role of mitochondria in cardiovascular diseases. Biology (Basel) 9: 9, 2020.

113. Ali AT, Idaghdour Y and Hodgkinson A: Analysis of mitochondrial m1A/G RNA modification reveals links to nuclear genetic variants and associated disease processes. Commun Biol 3: 147, 2020.

114. Xu L, Liu X, Sheng N, Oo KS, Liang J, Chionh YH, Xu J, Ye F, Gao YG, Dedon PC, et al: Three distinct 3-methylcytidine (m3C) methyltransferases modify tRNA and mRNA in mice and humans. J Biol Chem 292: 14695-14703, 2017.
115. Chen Z, Qi M, Shen B, Luo G, Wu Y, Li J, Lu Z, Zheng Z, Dai Q and Wang H: Transfer RNA demethylase ALKBH3 promotes cancer progression via induction of tRNA-derived small RNAs. Nucleic Acids Res 47: 2533-2545, 2019.

116. Ma CJ, Ding JH, Ye TT, Yuan BF, Feng YQ and Alk B: AlkB homologue 1 demethylates N3-methylcytidine in mRNA of mammals. ACS Chem Biol 14: 1418-1425, 2019.

117. Lentini JM, Alsaif HS, Faqeih E, Alkuraya FS and Fu D: DALRD3 encodes a protein mutated in epileptic encephalopathy that targets arginine tRNAs for 3-methylcytosine modification. Nat Commun 11: 2510, 2020.

118. Yang X, Yang Y, Sun BF, Chen YS, Xu JW, Lai WY, Li A, Wang X, Bhattarai DP, Xiao W, et al: 5-methylcytosine promotes mRNA export - NSUN2 as the methyltransferase and ALYREF as an m5C reader. Cell Res 27: 606-625, 2017.

119. Gambaryan AS, Venkstern TV and Baev AA: Use of the method of mixed substrates to study the specificity of tRNA methylases. Mol Biol (Mosk) 10: 697-705, 1976.

120. Amort T, Rieder D, Wille A, Khokhlova-Cubberley D, Riml C, Trixl L, Jia XY, Micura R and Lusser A: Distinct 5-methylcytosine profiles in poly(A) RNA from mouse embryonic stem cells and brain. Genome Biol 18: 1, 2017.

121. Squires JE, Patel HR, Nousch M, Sibbritt T, Humphreys DT, Parker BJ, Suter CM and Preiss T: Widespread occurrence of 5-methylcytosine in human coding and non-coding RNA. Nucleic Acids Res 40: 5023-5033, 2012.

122. Sharma S, Yang J, Watzinger P, Kötter P and Entian KD: Yeast Nop2 and Rcm1 methylate C2870 and C2278 of the 25S rRNA, respectively. Nucleic Acids Res 41: 9062-9076, 2013.

123. Brzezicha B, Schmidt M, Makalowska I, Jarmolowski A, Pienkowska J and Szweykowska-Kulinska Z: Identification of human tRNA:m5C methyltransferase catalysing intron-dependent $\mathrm{m} 5 \mathrm{C}$ formation in the first position of the anticodon of the pre-tRNA Leu (CAA). Nucleic Acids Res 34: 6034-6043, 2006

124. Hussain S, Sajini AA, Blanco S, Dietmann S, Lombard P, Sugimoto Y, Paramor M, Gleeson JG, Odom DT, Ule J, et al: NSun2-mediated cytosine-5 methylation of vault noncoding RNA determines its processing into regulatory small RNAs. Cell Rep 4: 255-261, 2013.

125. Haag S, Sloan KE, Ranjan N, Warda AS, Kretschmer J, Blessing C, Hübner B, Seikowski J, Dennerlein S, Rehling P, et al: NSUN3 and ABH1 modify the wobble position of mt-tRNAMet to expand codon recognition in mitochondrial translation. EMBO J 35: 2104-2119, 2016.

126. Metodiev MD, Spåhr H, Loguercio Polosa P, Meharg C, Becker C, Altmueller J, Habermann B, Larsson NG and Ruzzenente B: NSUN4 is a dual function mitochondrial protein required for both methylation of $12 \mathrm{~S}$ rRNA and coordination of mitoribosomal assembly. PLoS Genet 10: e1004110, 2014

127. Schosserer M, Minois N, Angerer TB, Amring M, Dellago H, Harreither E, Calle-Perez A, Pircher A, Gerstl MP, Pfeifenberger S, et al: Methylation of ribosomal RNA by NSUN5 is a conserved mechanism modulating organismal lifespan. Nat Commun 6: 6158, 2015

128. Haag S, Warda AS, Kretschmer J, Günnigmann MA, Höbartner C and Bohnsack MT: NSUN6 is a human RNA methyltransferase that catalyzes formation of $\mathrm{m} 5 \mathrm{C} 72$ in specific tRNÂs. RNA 21: 1532-1543, 2015

129. Kaiser S, Jurkowski TP, Kellner S, Schneider D, Jeltsch A and Helm M: The RNA methyltransferase Dnmt2 methylates DNA in the structural context of a tRNA. RNA Biol 14: 1241-1251, 2017.

130. Goll MG, Kirpekar F, Maggert KA, Yoder JA, Hsieh CL, Zhang X, Golic KG, Jacobsen SE and Bestor TH: Methylation of tRNAAsp by the DNA methyltransferase homolog Dnmt2. Science 311: 395-398, 2006.

131. Abbasi-Moheb L, Mertel S, Gonsior M, Nouri-Vahid L, Kahrizi K, Cirak S, Wieczorek D, Motazacker MM, Esmaeeli-Nieh S, Cremer K, et al: Mutations in NSUN2 cause autosomal-recessive intellectual disability. Am J Hum Genet 90: 847-855, 2012

132. Frye $M$ and Watt FM: The RNA methyltransferase Misu (NSun2) mediates Myc-induced proliferation and is upregulated in tumors. Curr Biol 16: 971-981, 2006.

133. Yi J, Gao R, Chen Y, Yang Z, Han P, Zhang H, Dou Y, Liu W, Wang W, Du G, et al: Overexpression of NSUN2 by DNA hypomethylation is associated with metastatic progression in human breast cancer. Oncotarget 8: 20751-20765,2017. 
134. Forbes SA, Beare D, Boutselakis H, Bamford S, Bindal N, Tate J, Cole CG, Ward S, Dawson E, Ponting L, et al: COSMIC Somatic cancer genetics at high-resolution. Nucleic Acids Res 45: D777-D783, 2017.

135. Elhardt W, Shanmugam R, Jurkowski TP and Jeltsch A: Somatic cancer mutations in the DNMT2 tRNA methyltransferase alter its catalytic properties. Biochimie 112: 66-72, 2015

136. Ghanbarian H, Wagner N, Polo B, Baudouy D, Kiani J, Michiels JF, Cuzin F, Rassoulzadegan M and Wagner KD: Dnmt2/Trdmt1 as mediator of RNA polymerase II transcriptional activity in cardiac growth. PLoS One 11: e0156953, 2016.

137. Luo Y, Feng J, Xu Q, Wang W and Wang X: NSun2 deficiency protects endothelium from inflammation via mRNA methylation of ICAM-1. Circ Res 118: 944-956, 2016.

138. Wang N, Tang H, Wang X, Wang W and Feng J: Homocysteine upregulates interleukin-17A expression via NSun2-mediated RNA methylation in T lymphocytes. Biochem Biophys Res Commun 493: 94-99, 2017.

139. Yuan S, Tang H, Xing J, Fan X, Cai X, Li Q, Han P, Luo Y, Zhang Z, Jiang B, et al: Methylation by NSun2 represses the levels and function of microRNA 125b. Mol Cell Biol 34: 3630-3641, 2014

140. Wen P, Cao H, Fang L, Ye H, Zhou Y, Jiang L, Su W, Xu H, $\mathrm{He} \mathrm{W}$, Dai C, et al: miR-125b/Ets1 axis regulates transdifferentiation and calcification of vascular smooth muscle cells in a high-phosphate environment. Exp Cell Res 322: 302-312, 2014.

141. Goettsch C, Rauner M, Pacyna N, Hempel U, Bornstein SR and Hofbauer LC: miR-125b regulates calcification of vascular smooth muscle cells. Am J Pathol 179: 1594-1600, 2011.

142. Trixl L and Lusser A: The dynamic RNA modification 5-methylcytosine and its emerging role as an epitranscriptomic mark. Wiley Interdiscip Rev RNA 10: e1510, 2019.

143. Jacob R, Zander S and Gutschner T: The dark side of the epitranscriptome: Chemical modifications in long non-coding RNAs. Int J Mol Sci 18: 18, 2017.

144.Fu L, Guerrero CR, Zhong N, Amato NJ, Liu Y, Liu S, Cai Q, Ji D, Jin SG, Niedernhofer LJ, et al: Tet-mediated formation of 5-hydroxymethylcytosine in RNA. J Am Chem Soc 136 $11582-11585,2014$

145. Fang S, Li J, Xiao Y, Lee M, Guo L, Han W, Li T, Hill MC, Hong T, Mo W, et al: Tet inactivation disrupts YY1 binding and long-range chromatin interactions during embryonic heart development. Nat Commun 10: 4297, 2019.

146. Ramanathan A, Robb GB and Chan S-H: mRNA capping: Biological functions and applications. Nucleic Acids Res 44 7511-7526, 2016

147.Furuichi Y: Discovery of $\mathrm{m}(7) \mathrm{G}$-cap in eukaryotic mRNAs. Proc Jpn Acad, Ser B, Phys Biol Sci 91: 394-409, 2015.

148. Pandolfini L, Barbieri I, Bannister AJ, Hendrick A, Andrews B, Webster N, Murat P, Mach P, Brandi R, Robson SC, et al: METTL1 promotes let-7 MicroRNA processing via m7G methylation. Mol Cell 74: 1278-1290.e9, 2019.

149. Bao MH, Feng X, Zhang YW, Lou XY, Cheng Y and Zhou HH Let-7 in cardiovascular diseases, heart development and cardiovascular differentiation from stem cells. Int J Mol Sci 14 23086-23102, 2013

150. Bernstein DL, Jiang X and Rom S: let-7 microRNAs: Their role in cerebral and cardiovascular diseases, inflammation, cancer, and their regulation. Biomedicines 9: 9, 2021.

151. Tolonen A-M, Magga J, Szabó Z, Viitala P, Gao E, Moilanen AM, Ohukainen P, Vainio L, Koch WJ, Kerkelä R, et al: Inhibition of Let-7 microRNA attenuates myocardial remodeling and improves cardiac function postinfarction in mice. Pharmacol Res Perspect 2: e00056-e00056, 2014.

152. Yang Y, Ago T, Zhai P, Abdellatif $M$ and Sadoshima $J$ Thioredoxin 1 negatively regulates angiotensin II-induced cardiac hypertrophy through upregulation of miR-98/let-7. Circ Res 108: 305-313, 2011.

153. Satoh M, Minami Y, Takahashi Y, Tabuchi T and Nakamura M: A cellular microRNA, let-7i, is a novel biomarker for clinical outcome in patients with dilated cardiomyopathy. J Card Fail 17: 923-929, 2011

154. Dimitrova DG, Teysset L and Carré C: RNA 2'-O-Methylation (Nm) modification in human diseases. Genes (Basel) 10: 10, 2019

155. Somme J, Van Laer B, Roovers M, Steyaert J, Versées W and Droogmans L: Characterization of two homologous 2'-O-methyltransferases showing different specificities for their tRNA substrates. RNA 20: 1257-1271, 2014

156. Cavaillé J, Nicoloso M and Bachellerie J-P: Targeted ribose methylation of RNA in vivo directed by tailored antisense RNA guides. Nature 383: 732-735, 1996.
157. O'Brien JE Jr, Kibiryeva N, Zhou X-G, Marshall JA, Lofland GK, Artman M, Chen J and Bittel DC: Noncoding RNA expression in myocardium from infants with tetralogy of Fallot. Circ Cardiovasc Genet 5: 279-286, 2012

158. Nagasawa C, Ogren A, Kibiryeva N, Marshall J, O'Brien JE Jr, Kenmochi $\mathrm{N}$ and Bittel DC: The role of scaRNAs in adjusting alternative mRNA splicing in heart development. J Cardiovasc Dev Dis 5: 26, 2018.

159. Elliott BA, Ho H-T, Ranganathan SV, Vangaveti S, Ilkayeva O, Abou Assi H, Choi AK, Agris PF and Holley CL: Modification of messenger RNA by 2'-O-methylation regulates gene expression in vivo. Nat Commun 10: 3401, 2019.

160. Gagnidze K, Rayon-Estrada V, Harroch S, Bulloch K and Papavasiliou FN: A new chapter in genetic medicine: RNA Editing and its role in disease pathogenesis. Trends Mol Med 24: 294-303, 2018

161. Nishikura K: A-to-I editing of coding and non-coding RNAs by ADARs. Nat Rev Mol Cell Biol 17: 83-96, 2016.

162. Uchida S and Jones SP: RNA editing: Unexplored opportunities in the cardiovascular system. Circ Res 122: 399-401, 2018.

163. Picardi E, Manzari C, Mastropasqua F, Aiello I, D'Erchia AM and Pesole G: Profiling RNA editing in human tissues: Towards the inosinome Atlas. Sci Rep 5: 14941, 2015.

164. Sukhova GK, Zhang Y, Pan JH, Wada Y, Yamamoto T, Naito M, Kodama T, Tsimikas S, Witztum JL, Lu ML, et al: Deficiency of cathepsin $\mathrm{S}$ reduces atherosclerosis in LDL receptor-deficient mice. J Clin Invest 111: 897-906, 2003.

165. Wang B, Sun J, Kitamoto S, Yang M, Grubb A, Chapman HA, Kalluri R and Shi GP: Cathepsin S controls angiogenesis and tumor growth via matrix-derived angiogenic factors. J Biol Chem 281: 6020-6029, 2006.

166.Zhu Y, Pirnie SP and Carmichael GG: High-throughput and site-specific identification of 2'-O-methylation sites using ribose oxidation sequencing (RibOxi-seq). RNA 23: 1303-1314, 2017.

167. Stellos K, Gatsiou A, Stamatelopoulos K, Perisic Matic L, John D, Lunella FF, Jaé N, Rossbach O, Amrhein C, Sigala F, et al: Adenosine-to-inosine RNA editing controls cathepsin $\mathrm{S}$ expression in atherosclerosis by enabling HuR-mediated post-transcriptional regulation. Nat Med 22: 1140-1150, 2016.

168. Wang Y, Men M, Xie B, Shan J, Wang C, Liu J, Zheng H, Yang W, Xue $S$ and Guo C: Inhibition of PKR protects against $\mathrm{H}_{2} \mathrm{O}_{2}$-induced injury on neonatal cardiac myocytes by attenuating apoptosis and inflammation. Sci Rep 6: 38753, 2016.

169. Moore JB IV, Sadri G, Fischer AG, Weirick T, Militello G, Wysoczynski M, Gumpert AM, Braun T and Uchida S: The A-to-I RNA editing enzyme Adar1 is essential for normal embryonic cardiac growth and development. Circ Res 127: 550-552, 2020.

170.El Azzouzi H, Vilaça AP, Feyen DA, Gommans WM, de Weger RA, Doevendans PA and Sluijter JP: Cardiomyocyte specific deletion of ADAR1 causes severe cardiac dysfunction and increased lethality. Front Cardiovasc Med 7: 30, 2020.

171. Stulić M and Jantsch MF: Spatio-temporal profiling of Filamin A RNA-editing reveals ADAR preferences and high editing levels outside neuronal tissues. RNA Biol 10: 1611-1617, 2013

172. Jain M, Mann TD, Stulić M, Rao SP, Kirsch A, Pullirsch D, Strobl X, Rath C, Reissig L, Moreth K, et al: RNA editing of Filamin A pre-mRNA regulates vascular contraction and diastolic blood pressure. EMBO J 37: 37, 2018.

173. Vu LT and Tsukahara T: C-to-U editing and site-directed RNA editing for the correction of genetic mutations. Biosci Trends 11 243-253, 2017.

174. Gerber AP and Keller W: RNA editing by base deamination: More enzymes, more targets, new mysteries. Trends Biochem Sci 26: 376-384, 2001.

175. Rosenberg BR, Dewell S and Papavasiliou FN: Identifying mRNA editing deaminase targets by RNA-Seq. Methods Mol Biol 718: 103-119, 2011

176. Powell LM, Wallis SC, Pease RJ, Edwards YH, Knott TJ and Scott J: A novel form of tissue-specific RNA processing produces apolipoprotein-B48 in intestine. Cell 50: 831-840, 1987.

177. Teng B, Burant CF and Davidson NO: Molecular cloning of an apolipoprotein B messenger RNA editing protein. Science 260: 1816-1819, 1993

178. Blanc V and Davidson NO: APOBEC-1-mediated RNA editing. Wiley Interdiscip Rev Syst Biol Med 2: 594-602, 2010.

179. Anant S, Henderson JO, Mukhopadhyay D, Navaratnam N, Kennedy S, Min J and Davidson NO: Novel role for RNA-binding protein CUGBP2 in mammalian RNA editing. CUGBP2 modulates $\mathrm{C}$ to $\mathrm{U}$ editing of apolipoprotein $\mathrm{B}$ mRNA by interacting with apobec- 1 and ACF, the apobec-1 complementation factor. J Biol Chem 276: 47338-47351, 2001 
180.Blech-Hermoni Y, Dasgupta T, Coram RJ and Ladd AN Identification of targets of CUG-BP, Elav-like family member 1 (CELF1) regulation in embryonic heart muscle. PLoS One 11: e0149061, 2016

181. Giudice J, Xia Z, Li W and Cooper TA: Neonatal cardiac dysfunction and transcriptome changes caused by the absence of Celf1. Sci Rep 6: 35550, 2016.

182. Liao W, Hong SH, Chan BH, Rudolph FB, Clark SC and Chan L: APOBEC-2, a cardiac- and skeletal muscle-specific member of the cytidine deaminase supergene family. Biochem Biophys Res Commun 260: 398-404, 1999.

183. Sharma S, Patnaik SK, Taggart RT, Kannisto ED, Enriquez SM, Gollnick P and Baysal BE: APOBEC3A cytidine deaminase induces RNA editing in monocytes and macrophages. Nat Commun 6: 6881, 2015.

184. Sharma S, Patnaik SK, Kemer Z and Baysal BE: Transient overexpression of exogenous APOBEC3A causes C-to-U RNA editing of thousands of genes. RNA Biol 14: 603-610, 2017.

185.Li X, Ma S and Yi C: Pseudouridine: The fifth RNA nucleotide with renewed interests. Curr Opin Chem Biol 33: 108-116, 2016

186. Cohn WE and Volkin E: Nucleoside-5'-phosphates from ribonucleic acid. Nature 167: 483-484, 1951.

187. Sengupta R, Vainauskas S, Yarian C, Sochacka E, Malkiewicz A, Guenther RH, Koshlap KM and Agris PF: Modified constructs of the tRNA TPsiC domain to probe substrate conformational requirements of $\mathrm{m}(1) \mathrm{A}(58)$ and $\mathrm{m}(5) \mathrm{U}(54)$ tRNA methyltransferases. Nucleic Acids Res 28: 1374-1380, 2000.

188. Charette M and Gray MW: Pseudouridine in RNA: What, where, how, and why. IUBMB Life 49: 341-351, 2000.

189. Davis DR: Stabilization of RNA stacking by pseudouridine. Nucleic Acids Res 23: 5020-5026, 1995.

190. Karijolich J and Yu YT: Converting nonsense codons into sense codons by targeted pseudouridylation. Nature 474: 395-398, 2011

191. Spenkuch F, Motorin Y and Helm M: Pseudouridine: Still mysterious, but never a fake (uridine)! RNA Biol 11: 1540-1554, 2014

192. Safra M, Nir R, Farouq D, Vainberg Slutskin I and Schwartz S: TRUB1 is the predominant pseudouridine synthase acting on mammalian mRNA via a predictable and conserved code. Genome Res 27: 393-406, 2017

193. Antonicka H, Choquet K, Lin ZY, Gingras AC, Kleinman CL and Shoubridge EA: A pseudouridine synthase module is essential for mitochondrial protein synthesis and cell viability. EMBO Rep 18: 28-38, 2017.

194.Zaganelli S, Rebelo-Guiomar P, Maundrell K, Rozanska A, Pierredon S, Powell CA, Jourdain AA, Hulo N, Lightowlers RN, Chrzanowska-Lightowlers ZM, et al: The pseudouridine synthase RPUSD4 is an essential component of mitochondrial RNA granules. J Biol Chem 292: 4519-4532, 2017.

195. Mei YP, Liao JP, Shen J, Yu L, Liu BL, Liu L, Li RY, Ji L, Dorsey SG, Jiang ZR, et al: Small nucleolar RNA 42 acts as an oncogene in lung tumorigenesis. Oncogene 31: 2794-2804, 2012

196. Bykhovskaya Y, Casas K, Mengesha E, Inbal A and Fischel-Ghodsian N: Missense mutation in pseudouridine synthase 1 (PUS1) causes mitochondrial myopathy and sideroblastic anemia (MLASA). Am J Hum Genet 74: 1303-1308, 2004

197.Zucchini C, Strippoli P, Biolchi A, Solmi R, Lenzi L, D'Addabbo P, Carinci P and Valvassori L: The human TruB family of pseudouridine synthase genes, including the Dyskeratosis Congenita 1 gene and the novel member TRUB1 Int J Mol Med 11: 697-704, 2003.

198. Jády BE and Kiss T: A small nucleolar guide RNA functions both in 2'-O-ribose methylation and pseudouridylation of the U5 spliceosomal RNA. EMBO J 20: 541-551, 2001

199. Darzacq X, Jády BE, Verheggen C, Kiss AM, Bertrand E and Kiss T: Cajal body-specific small nuclear RNAs: A novel class of 2'-O-methylation and pseudouridylation guide RNAs EMBO J 21: 2746-2756, 2002.

200. Nagasawa CK, Kibiryeva N, Marshall J, O'Brien JE Jr and Bittel DC: scaRNA1 levels alter pseudouridylation in spliceosomal RNA U2 affecting alternative mRNA splicing and embryonic development. Pediatr Cardiol 41: 341-349, 2020.

201. Wilusz JE: Long noncoding RNAs: Re-writing dogmas of RNA processing and stability. Biochim Biophys Acta 1859: 128-138, 2016.

202. Kanvah S, Joseph J, Schuster GB, Barnett RN, Cleveland CL and Landman U: Oxidation of DNA: Damage to nucleobases. Acc Chem Res 43: 280-287, 2010.

203. Faucher F, Doublié S and Jia Z: 8-oxoguanine DNA glycosylases: One lesion, three subfamilies. Int J Mol Sci 13: 6711-6729, 2012
204. Shah A, Gray K, Figg N, Finigan A, Starks L and Bennett M Defective base excision repair of oxidative DNA damage in vascular smooth muscle cells promotes atherosclerosis. Circulation 138: 1446-1462, 2018.

205. Seok H, Lee H, Lee S, Ahn SH, Lee HS, Kim GD, Peak J, Park J, Cho YK, Jeong Y, et al: Position-specific oxidation of miR-1 encodes cardiac hypertrophy. Nature 584: 279-285, 2020.

206. Wang J, Wang Q, Watson LJ, Jones SP and Epstein PN: Cardiac overexpression of 8-oxoguanine DNA glycosylase 1 protects mitochondrial DNA and reduces cardiac fibrosis following transaortic constriction. Am J Physiol Heart Circ Physiol 301: H2073-H2080, 2011.

207. Noren Hooten N, Ejiogu N, Zonderman AB and Evans MK: Association of oxidative DNA damage and C-reactive protein in women at risk for cardiovascular disease. Arterioscler Thromb Vasc Biol 32: 2776-2784, 2012.

208. Motorin Y and Helm M: RNA nucleotide methylation. Wiley Interdiscip Rev RNA 2: 611-631, 2011.

209. Garcia-Campos MA, Edelheit S, Toth U, Safra M, Shachar R, Viukov S, Winkler R, Nir R, Lasman L, Brandis A, et al: Deciphering the 'm6A Code' via antibody-independent quantitative profiling. Cell 178: 731-747.e16, 2019.

210. Zhang Z, Chen L-Q, Zhao Y-L, Yang CG, Roundtree IA, Zhang Z, Ren J, Xie W, He C and Luo GZ: Single-base mapping of m6A by an antibody-independent method. Sci Adv 5: eaax0250, 2019

211. Liu N and Pan T: Probing N6-methyladenosine (m6A) RNA modification in total RNA with SCARLET. Methods Mol Biol 1358: 285-292, 2016.

212. Dominissini D, Moshitch-Moshkovitz S, Salmon-Divon M, Amariglio N and Rechavi G: Transcriptome-wide mapping of $\mathrm{N}(6)$-methyladenosine by $\mathrm{m}(6) \mathrm{A}-\mathrm{seq}$ based on immunocapturing and massively parallel sequencing. Nat Protoc 8: 176-189, 2013.

213. Chen K, LuZ, Wang X,Fu Y,LuoGZ,Liu N,HanD,DominissiniD, Dai Q, Pan T, et al: High-resolution N(6)-methyladenosine (m(6) A) map using photo-crosslinking-assisted m(6) A sequencing. Angew Chem Int Ed Engl 54: 1587-1590, 2015.

214. Marchand V, Bourguignon-Igel V, Helm M and Motorin Y: Analysis of pseudouridines and other RNA modifications using HydraPsiSeq protocol. Methods: Sep 1, 2021 (Epub ahead of print). doi: 10.1016/j.ymeth.2021.08.008.

215. Motorin Y and Helm M: Methods for RNA modification mapping using deep sequencing: Established and new emerging technologies. Genes (Basel) 10: 35, 2019.

216. Dai Q, Moshitch-Moshkovitz S, Han D, Kol N, Amariglio N, Rechavi G,Dominissini D and HeC: Nm-seq maps 2'-O-methylation sites in human mRNA with base precision. Nat Methods 14: 695-698, 2017

217. Birkedal U,Christensen-Dalsgaard M,Krogh N, Sabarinathan R Gorodkin $\mathrm{J}$ and Nielsen $\mathrm{H}$ : Profiling of ribose methylations in RNA by high-throughput sequencing. Angew Chem Int Ed Engl 54: 451-455, 2015.

218. Yoluç Y, Ammann G, Barraud P, Jora M, Limbach PA, Motorin Y, Marchand V, Tisné C, Borland K and Kellner S: Instrumental analysis of RNA modifications. Crit Rev Biochem Mol Biol 56: 178-204, 2021.

219. Huang TY, Liu J and McLuckey SA: Top-down tandem mass spectrometry of tRNA via ion trap collision-induced dissociation. J Am Soc Mass Spectrom 21: 890-898, 2010

220. Durairaj A and Limbach PA: Improving CMC-derivatization of pseudouridine in RNA for mass spectrometric detection. Anal Chim Acta 612: 173-181, 2008

221. Kowalak JA, Pomerantz SC, Crain PF and McCloskey JA: A novel method for the determination of post-transcriptional modification in RNA by mass spectrometry. Nucleic Acids Res 21: 4577-4585, 1993.

222. Heiss M, Borland K, Yoluc Y $Y$ and Kellner S: Quantification of Modified nucleosides in the context of NAIL-MS. Methods Mol Biol 2298: 279-306, 2021.

223. Wein S, Andrews B, Sachsenberg T, Santos-Rosa H, KohlbacherO, Kouzarides T, Garcia BA and Weisser H: A computational platform for high-throughput analysis of RNA sequences and modifications by mass spectrometry. Nat Commun 11: 926, 2020.

224. Marceca GP, Tomasello L, Distefano R, Acunzo M, Croce CM and Nigita G: Detecting and characterizing A-To-I microRNA editing in cancer. Cancers (Basel) 13: 1699, 2021.

225. Okada S, Ueda H, Noda Y and Suzuki T: Transcriptome-wide identification of A-to-I RNA editing sites using ICE-seq. Methods 156: 66-78, 2019. 
226. Adachi H, DeZoysa MD and Yu YT: Detection and quantification of pseudouridine in RNA. In: Epitranscriptomics: Methods and Protocols. Wajapeyee N and Gupta R (eds). Springer, New York, NY, pp219-235, 2019.

227. Schwartz S, Bernstein DA, Mumbach MR, Jovanovic M, Herbst RH, León-Ricardo BX, Engreitz JM, Guttman M, Satija R, Lander ES, et al: Transcriptome-wide mapping reveals widespread dynamic-regulated pseudouridylation of ncRNA and mRNA. Cell 159: 148-162, 2014.

228. Lovejoy AF, Riordan DP and Brown PO: Transcriptome-wide mapping of pseudouridines: Pseudouridine synthases modify specific mRNAs in S. cerevisiae. PLoS One 9: e110799, 2014.

229. Carlile TM, Rojas-Duran MF, Zinshteyn B, Shin H, Bartoli KM and Gilbert WV: Pseudouridine profiling reveals regulated mRNA pseudouridylation in yeast and human cells. Nature 515: 143-146, 2014.

230.Li X, Zhu P, Ma S, Song J, Bai J, Sun F and Yi C: Chemical pulldown reveals dynamic pseudouridylation of the mammalian transcriptome. Nat Chem Biol 11: 592-597, 2015.

231. Banerjee A, Mikhailova E, Cheley S, Gu LQ, Montoya M, Nagaoka Y, Gouaux E and Bayley H: Molecular bases of cyclodextrin adapter interactions with engineered protein nanopores. Proc Natl Acad Sci USA 107: 8165-8170, 2010.

232.Wang Y, Yang Q and Wang Z: The evolution of nanopore sequencing. Front Genet 5: 449-449, 2015

233. Simpson JT, Workman RE, Zuzarte PC, David M, Dursi LJ and Timp W: Detecting DNA cytosine methylation using nanopore sequencing. Nat Methods 14: 407-410, 2017.

234. Vlachakis D, Papakonstantinou E, Sagar R, Bacopoulou F, Exarchos T, Kourouthanassis P, Karyotis V, Vlamos P, Lyketsos C, Avramopoulos D, et al: Improving the utility of polygenic risk scores as a biomarker for Alzheimer's disease. Cells 10: 1627, 2021.

235. Buniello A, MacArthur JAL, Cerezo M, Harris LW, Hayhurst J, Malangone C, McMahon A, Morales J, Mountjoy E, Sollis E, et al: The NHGRI-EBI GWAS Catalog of published genome-wide association studies, targeted arrays and summary statistics 2019. Nucleic Acids Res 47: D1005-D1012, 2019.

236.Zheng Y, Nie P, Peng D, He Z, Liu M, Xie Y, Miao Y, Zuo Z and Ren J: m6AVar: A database of functional variants involved in m6A modification. Nucleic Acids Res 46: D139-D145, 2018.

237.Jiang S, Xie Y, He Z, Zhang Y, Zhao Y, Chen L, Zheng Y, Miao Y, Zuo Z and Ren J: m6ASNP: A tool for annotating genetic variants by m6A function. Gigascience 7: 7, 2018.

238. Song B, Tang Y, Chen K, WeiZ, Rong R, Lu Z, Su J, de Magalhães JP, Rigden DJ and Meng J: m7GHub: Deciphering the location, regulation and pathogenesis of internal mRNA N7-methylguanosine (m7G) sites in human. Bioinformatics 36: 3528-3536, 2020

239. Chen K, Song B, Tang Y, Wei Z, Xu Q, Su J, de Magalhães JP, Rigden DJ and Meng J: RMDisease: A database of genetic variants that affect RNA modifications, with implications for epitranscriptome pathogenesis. Nucleic Acids Res 49: D1396-D1404, 2021.

240. Incarnato D, Morandi E, Simon LM and Oliviero S: RNA Framework: An all-in-one toolkit for the analysis of RNA structures and post-transcriptional modifications. Nucleic Acids Res 46: e97, 2018.

241. Mo XB, Lei SF, Zhang YH and Zhang H: Detection of m6A-associated SNPs as potential functional variants for coronary artery disease. Epigenomics 10: 1279-1287, 2018.

242. Mo XB, Lei SF, Zhang YH and Zhang H: Examination of the associations between m6A-associated single-nucleotide polymorphisms and blood pressure. Hypertens Res 42: 1582-1589, 2019.

243. Mo X, Lei S, Zhang Y and Zhang H: Genome-wide enrichment of m6A-associated single-nucleotide polymorphisms in the lipid loci. Pharmacogenomics J 19: 347-357, 2019.

244. Mo X-B, Lei S-F, Zhang Y-H and Zhang H: Integrative Analysis identified IRF6 and NDST1 as potential causal genes for ischemic stroke. Front Neurol 10: 517, 2019.

245. Nielsen JB, Thorolfsdottir RB, Fritsche LG, Zhou W, Skov MW, Graham SE, Herron TJ, McCarthy S, Schmidt EM, Sveinbjornsson $\mathrm{G}$, et al: Biobank-driven genomic discovery yields new insight into atrial fibrillation biology. Nat Genet 50 : 1234-1239, 2018

246. Ehret GB, Ferreira T, Chasman DI, Jackson AU, Schmidt EM, Johnson T, Thorleifsson G, Luan J, Donnelly LA, Kanoni S, et al; CHARGE-EchoGen consortium; CHARGE-HF consortium; Wellcome Trust Case Control Consortium: The genetics of blood pressure regulation and its target organs from association studies in 342,415 individuals. Nat Genet 48: 1171-1184, 2016.
247. Franzén O, Ermel R, Sukhavasi K, Jain R, Jain A, Betsholtz C, Giannarelli C, Kovacic JC, Ruusalepp A, Skogsberg J, et al: Global analysis of A-to-I RNA editing reveals association with common disease variants. PeerJ 6: e4466-e4466, 2018.

248. Lee JY, Lee BS, Shin DJ, Woo Park K, Shin YA, Joong Kim K, Heo L, Young Lee J, Kyoung Kim Y, Jin Kim Y, et al: A genome-wide association study of a coronary artery disease risk variant. J Hum Genet 58: 120-126, 2013.

249. Jeemon P, Pettigrew K, Sainsbury C, Prabhakaran D and Padmanabhan S: Implications of discoveries from genome-wide association studies in current cardiovascular practice. World J Cardiol 3: 230-247, 2011.

250. Wakil SM, Ram R, Muiya NP, Mehta M, Andres E, Mazhar N, Baz B, Hagos S, Alshahid M, Meyer BF, et al: A genome-wide association study reveals susceptibility loci for myocardial infarction/ coronary artery disease in Saudi Arabs. Atherosclerosis 245: 62-70, 2016.

251. Terasawa Y, Ladha Z, Leonard SW, Morrow JD, Newland D, Sanan D, Packer L, Traber MG and Farese RV Jr: Increased atherosclerosis in hyperlipidemic mice deficient in alpha -tocopherol transfer protein and vitamin E. Proc Natl Acad Sci USA 97: 13830-13834, 2000

252. Lu N, Li X, Yu J, Li Y, Wang C, Zhang L, Wang T and Zhong X: Curcumin attenuates lipopolysaccharide-induced hepatic lipid metabolism disorder by modification of m6A RNA methylation in piglets. Lipids 53: 53-63, 2018.

253. Sikorski V, Karjalainen P, Blokhina D, Oksaharju K, Khan J, Katayama S, Rajala H, Suihko S, Tuohinen S, Teittinen K, et al: Epitranscriptomics of ischemicheartdisease-the IHD-EPITRAN study design and objectives. Int J Mol Sci 22: 22, 2021.

254. Huang Y, Yan J, Li Q, Li J, Gong S, Zhou H, Gan J, Jiang H, Jia GF, Luo C, et al: Meclofenamic acid selectively inhibits FTO demethylation of m6A over ALKBH5. Nucleic Acids Res 43: 373-384, 2015

255.Li J, Chen Z, Chen F, Xie G, Ling Y, Peng Y, Lin Y, Luo N, Chiang $\mathrm{CM}$ and Wang $\mathrm{H}$ : Targeted mRNA demethylation using an engineered dCas13b-ALKBH5 fusion protein. Nucleic Acids Res 48: 5684-5694, 2020.

256. Cox DBT, Gootenberg JS, Abudayyeh OO, Franklin B, Kellner MJ, Joung $J$ and Zhang F: RNA editing with CRISPRCas13. Science 358: 1019-1027, 2017.

257. Papageorgiou L, Cuong NT and Vlachakis D: Antibodies as stratagems against cancer. Mol Biosyst 12: 2047-2055, 2016.

258. Vlachakis D: Antibody clustering and 3D modelling for neurodegenerative diseases. In: Computational Neurodegeneration. Vlamos P, Kotsireas I and Tarnanas I (eds). Springer, New York, NY, pp1-13, 2020

259. Altaf F, Vesely C, Sheikh AM, Munir R, Shah ST and Tariq A: Modulation of ADAR mRNA expression in patients with congenital heart defects. PLoS One 14: e0200968, 2019.

260. van der Kwast RV, Quax PH and Nossent AY: An emerging role for isomiRs and the microRNA epitranscriptome in neovascularization. Cells 9: 9, 2019.

261.Dai DF, Chen T, Johnson SC, Szeto H and Rabinovitch PS: Cardiac aging: From molecular mechanisms to significance in human health and disease. Antioxid Redox Signal 16: 1492-1526, 2012.

262. McMahon M, Forester $\mathrm{C}$ and Buffenstein R: Aging through an epitranscriptomic lens. Nat Aging 1: 335-346, 2021.

263. Komal S, Zhang LR and Han SN: Potential regulatory role of epigenetic RNA methylation in cardiovascular diseases. Biomed Pharmacother 137: 111376, 2021.

264. Van Haute L, Dietmann S, Kremer L, Hussain S, Pearce SF, Powell CA, Rorbach J, Lantaff R, Blanco S, Sauer S, et al: Deficient methylation and formylation of mt-tRNA(Met) wobble cytosine in a patient carrying mutations in NSUN3. Nat Commun 7: 12039, 2016

265. Bohnsack MT and Sloan KE: The mitochondrial epitranscriptome: The roles of RNA modifications in mitochondrial translation and human disease. Cell Mol Life Sci 75: 241-260, 2018.

266. Vilardo E and Rossmanith W: Molecular insights into HSD10 disease: Impact of SDR 5C1 mutations on the human mitochondrial RNase P complex. Nucleic Acids Res 43: 6649, 2015.

267. Vlachakis D, Tsagrasoulis D, Megalooikonomou V and Kossida S: Introducing Drugster: A comprehensive and fully integrated drug design, lead and structure optimization toolkit. Bioinformatics 29: 126-128, 2013. 
268. Xu Z, Peng B, Cai Y, Wu G, Huang J, Gao M, Guo G, Zeng S, Gong $\mathrm{Z}$ and Yan Y: N6-methyladenosine RNA modification in cancer therapeutic resistance: Current status and perspectives. Biochem Pharmacol 182: 114258, 2020.

269. Tsaniras S and Vlachakis D: Diet, obesity and cancer. J Mol Biochem 4: 20, 2016.

270. Cui Q, Shi H, Ye P, Li L, Qu Q, Sun G, Sun G, Lu Z, Huang Y, Yang CG, et al: m6A RNA methylation regulates the self-renewal and tumorigenesis of glioblastoma stem cells. Cell Rep 18: 2622-2634, 2017.

271. Singh B, Kinne HE, Milligan RD, Washburn LJ, Olsen M and Lucci A: Important role of FTO in the survival of rare panresistant triple-negative inflammatory breast cancer cells facing a severe metabolic challenge. PLoS One 11: e0159072, 2016.

272. Charalampopoulou M, Syrigos K, Filopoulos E, Megalooikonomou V, Vlachakis D, Chrousos G and Darviri C: Reliability and validity of the instrument newly diagnosed breast cancer stress scale in the Greek population. J Mol Biochem 9 : $5-12,2020$.

273. Su R, Dong L, Li C, Nachtergaele S, Wunderlich M, Qing Y, Deng X, Wang Y, Weng X, Hu C, et al: R-2HG exhibits anti-tumor activity by targeting FTO/m6A/MYC/CEBPA signaling. Cell 172: 90-105.e23, 2018.

274.Huang Y, Su R, Sheng Y, Dong L, Dong Z, Xu H, Ni T, Zhang ZS, Zhang T, Li C, et al: Small-molecule targeting of oncogenic FTO demethylase in acute myeloid leukemia. Cancer Cell 35: 677-691.e10, 2019.

275. Floresta G, Pistarà V, Amata E, Dichiara M, Damigella A, Marrazzo A, Prezzavento O, Punzo F and Rescifina A: Molecular modeling studies of pseudouridine isoxazolidinyl nucleoside analogues as potential inhibitors of the pseudouridine 5'-monophosphate glycosidase. Chem Biol Drug Des 91: 519-525, 2018.
276. Vlachakis D, Fakourelis P, Megalooikonomou V, Makris C and Kossida S: DrugOn: A fully integrated pharmacophore modeling and structure optimization toolkit. PeerJ 3: e725, 2015.

277. Vlachakis D and Kossida S: Molecular modeling and pharmacophore elucidation study of the Classical Swine Fever virus helicase as a promising pharmacological target. PeerJ 1: e85, 2013.

278. Papageorgiou L, Loukatou S, Sofia K, Maroulis D and Vlachakis D: An updated evolutionary study of Flaviviridae NS3 helicase and NS5 RNA-dependent RNA polymerase reveals novel invariable motifs as potential pharmacological targets. Mol Biosyst 12: 2080-2093, 2016.

279. Papageorgiou L, Loukatou S, Koumandou VL, Makałowski W, Megalooikonomou V, Vlachakis D and Kossida S: Structural models for the design of novel antiviral agents against Greek Goat Encephalitis. PeerJ 2: e664, 2014.

280. Amidi S, Amidi A, Vlachakis D, Paragios N and Zacharaki EI Automatic single- and multi-label enzymatic function prediction by machine learning. PeerJ 5: e3095, 2017.

281. Marinou M, Platis D, Ataya FS, Chronopoulou E, Vlachakis D and Labrou NE: Structure-based design and application of a nucleotide coenzyme mimetic ligand: Application to the affinity purification of nucleotide dependent enzymes. J Chromatogr A 1535: 88-100, 2018.

282. Vlachakis D and Vlamos P: Mathematical multidimensional modelling and structural artificial intelligence pipelines provide insights for the designing of highly specific antiSARS-CoV2 agents. Math Comput Sci 15: 877-888, 2021.

(i) $\Theta$ This work is licensed under a Creative Commons Attribution-NonCommercial-NoDerivatives 4.0 International (CC BY-NC-ND 4.0) License. 